\title{
A
}

\section{Accountability of the Media} YOUNG MIN

Korea University

The accountability of the media is a normative notion that underlies the balance of freedom and social responsibility across media structure, performance, and product.

From the birth of the press, its freedom has been strongly connected with social expectations for the media to protect the public interest and to improve the quality of democracy ( $\rightarrow$ Freedom of the Press, Concept of). Fundamentally, it is a matter of balancing freedom and responsibility, and two measures have been used primarily for that purpose: the market and the law. Neither approach, however, has proven successful. The free market measures often fail to secure plurality in media ownership and diversity in media content. On the other hand, legal regulations, such as $\rightarrow$ censorship and other repressive measures legislated to protect the public good, often infringe freedom itself.

Many alternatives to these two approaches have been suggested. The theory of 'social responsibility' emphasizes the importance of media freedom to scrutinize power and to provide accurate information. It suggests that the media's obligations to society be fulfilled primarily by self-regulation, i.e., by the voluntary efforts of media owners and practitioners ( $\rightarrow$ Ethics in Journalism; Professionalization of Journalism). Although the theory contributed to the notion of media responsibility, it was not successful in detailing exactly how to hold the free market media socially responsible.

The concept of media accountability is a much wider concept than self-regulation, denoting both the media's legal obligation to prevent or reduce any negative consequences of its practices and its moral duty to provide quality service for the public. Accountability is also a process-oriented concept defining how the media answer, to whom, and for what.

There exist diverse ways of achieving media accountability, which include legal and legislative regulation, and involve the market, the civil society (or the public), and the media profession itself (McQuail 2003). To sum up: media accountability represents an effort to establish the rules by which the media perform socially expected functions in a democracy while preserving freedom and extending it to more people and incorporating more diverse voices.

See also: $>$ CENSORSHIP $>$ ETHICS IN JOURNALISM

FREEDOM OF THE PRESS, CONCEPT OF

PROFESSIONALIZATION OF JOURNALISM

The Concise Encyclopedia of Communication, First Edition. Edited by Wolfgang Donsbach. 


\section{REFERENCES AND SUGGESTED READINGS}

Bertrand, C.-J. (2005). Introduction: Media accountability. Pacific Journalism Review, 11(2), 5-16.

McQuail, D. (2003). Media accountability and freedom of publication. Oxford: Oxford University Press.

Merritt, M. \& McCombs, M. (2004). The two w's of journalism: The why and what of public affairs reporting. Mahwah, NJ: Lawrence Erlbaum.

\section{Accounting Research}

\author{
RICHARD BUTTNY \\ Syracuse University
}

Research on verbal accounting examines how language is used to explain or make sense of events. Citing one's motive or describing the context may serve to portray events in a different way - as understandable, excusable, or less culpable. An accounting can range from a lengthy $\rightarrow$ discourse (a narrative or courtroom cross-examination) to a single word or nonverbal substitute, e.g., a shoulder shrug. In routine circumstances accounts are not necessary; persons, actions, and events speak for themselves. The need for accounts arises when something problematic or out of the ordinary occurs. Another's question, challenge, or blame makes an account relevant from the actor (Goffman 1971).

Accounts 'for' actions arise in response to some troubles or blame; accounts attempt to remediate the incident or one's responsibility for it (Scott \& Lyman 1968). Excuses are a paradigmatic kind of account. Accounts may serve as a reason for why one did what one did. Accounts 'of' action involve a person's sense-making for events such as relationships, personal crises, or changes of life course. A story-like account or narrative would be the paradigmatic form. Narratives can account by conveying a temporal sequence of events, the cast of characters, and the actor's part in portraying events in a particular way $(\rightarrow$ Storytelling and Narration). This approach captures our need to interpret our lives, particularly in times of stress or trauma (Orbuch 1997).

Given that an accounting is offered to other(s), the recipient may honor the account or not. An account may not be addressed at all by the recipient. Alternatively the recipient may question the account, thereby prompting further accounts
( $\rightarrow$ Questions and Questioning). The larger the problematic event, the more likely it is that the actor's accounts will be questioned. Accounts are typically partial and selective, so it is difficult to tell the whole story in the initial accounting. Persons may be probed by recipients so that accounts get incrementally unpacked and expanded. Accountings are collaboratively achieved among interlocutors. Persons may alter their account as it is retold to different recipients.

\author{
See also: DIsCOURSE LANGUAGE AND \\ SOCIAL INTERACTION $>$ QUESTIONS AND \\ QUESTIONING $>$ STORYTELLING AND NARRATION
}

\section{REFERENCES AND SUGGESTED READING}

Goffman, E. (1971). Relations in public: Microstudies of the public order. New York: Harper \& Row.

Orbuch, T. L. (1997). People's accounts count: The sociology of accounts. Annual Review of Sociology, 23, 455-478.

Scott, M. L. \& Lyman, S. M. (1968). Accounts. American Sociological Review, 33, 46-62.

\section{Acculturation Processes and Communication}

\section{YOUNG YUN KIM}

University of Oklahoma

From immigrants and refugees seeking to build a new life in a foreign land to temporary sojourners such as international students and employees of multinational companies, numerous people change homes each year crossing cultural boundaries. Although unique in circumstances, all cultural strangers embark on the common project of acculturation: the learning, practicing, and internalizing of the symbols and routinized behaviors prevalent in the new cultural environment ( $\rightarrow$ Intercultural and Intergroup Communication).

The acculturation phenomenon often accompanies the experience of 'deculturation,' that is, at least temporary unlearning or replacement of some of the original cultural habits. The interplay of acculturation and deculturation experiences facilitates 'cross-cultural adaptation,' the process of internal change in the individual leading to 
a relatively stable, reciprocal, and functional relationship with a given host environment. Given sufficient time, even those who interact with natives with the intention of confining themselves to only superficial relationships are likely to be at least minimally adapted to the host culture "in spite of themselves" (Taft 1977, 150).

Since the 1930s, research on immigrant acculturation has been extensive across social science disciplines, and has produced ample empirical evidence documenting the long-term, cumulative adaptive change in individuals, the direction of assimilation, a state of psychological, social, and cultural convergence to those of the natives. Kim's (2001) integrative theory of cross-cultural adaptation, for example, offers a multidimensional model, in which cultural strangers' intrapersonal, interpersonal, and mass communication activities drive the dynamic and interactive process of becoming increasingly 'fit' in their psychological and functional relationship with the host environment.

The traditional cumulative-progressive trajectory has been challenged in recent decades by some investigators who conceive the acculturation-adaptation phenomenon from a pluralistic perspective on intergroup relations. Among the widely utilized pluralistic approaches is Berry's (1980) psychological theory of acculturation. Focusing on individuals' conscious or unconscious identity orientations with respect to their original culture and the host society, Berry's theory identifies four "acculturation strategies": "assimilation," "integration," "separation," and "marginalization."

\section{See also: C CULTURE: DEFINITIONS AND \\ CONCEPTS $>$ ETHNIC MEDIA AND THEIR \\ INFLUENCE INTERCULTURAL AND \\ INTERGROUP COMMUNICATION}

\section{REFERENCES AND SUGGESTED READINGS}

Berry, J. (1980). Acculturation as varieties of adaptation. In A. Padilla (ed.), Acculturation: theory: Models and some new findings. Washington, DC: Westview, pp. 9-25.

Kim, Y. Y. (2001). Becoming intercultural: An integrative theory of communication and cross-cultural adaptation. Thousand Oaks, CA: Sage.

Taft, R. (1977). Coping with unfamiliar cultures. In N. Warren (ed.), Studies in cross-cultural psychology, vol. 1. London: Academic Press, pp. 121-153.

\section{Action Assembly Theory}

JOHN O. GREENE

Purdue University

Action assembly theory (AAT) seeks to explain message behavior (both verbal and nonverbal) by describing the system of mental structures and processes that give rise to those behaviors ( $\rightarrow$ Message Production). As such, AAT is a member of the broader class of cognitive theories of message production ( $\rightarrow$ Cognitive Science). AAT, in turn, is itself an umbrella category for any of a variety of actual and potential specific theories that share certain central features, most prominently the notion that actions are created by integrating (or assembling) elemental features represented in long-term memory ( $\rightarrow$ Memory) in code systems representing multiple levels of abstraction. Two distinct exemplars of this class are found in Greene $(1984,1997)$.

In the language of AAT, 'action features', the fundamental building blocks of thought and overt action, are stored in memory in units called 'procedural records.' The theory then specifies two processes involved in making use of action features to produce messages: 'activation,' (the process by which features relevant to one's goals and ongoing activities are selected) and 'assembly' (the process of integrating activated features).

Because difficulties in assembly are held to be reflected in the time required to formulate and execute messages, a number of studies conducted within the AAT framework have examined speech fluency and speech rate $(\rightarrow$ Speech Fluency and Speech Errors). These studies include investigations of the impact of attempting to design messages that address multiple goals and the effects of advance message planning on speech fluency. Another program of research has examined the impact of practice, or skill acquisition, on the speed of message production. AAT has also been applied in studies of the nature of the self, communication apprehension, and the behavioral correlates of deception. Yet another series of studies informed by AAT has focused on 'creative facility' - individual differences in the ability to formulate novel, socially appropriate messages. Most recently, AAT has been brought to bear in theorizing about 'transcendent 
interactions' - conversations characterized by a deep sense of absorption and connection with one's interlocutor.

See also: COGNITIVE SCIENCE COMMUNICATION APPREHENSION $>$ COMMUNICATION SKILL ACQUISITION GOALS, COGNITIVE ASPECTS OF INTERPERSONAL COMMUNICATION COMPETENCE AND SOCIAL SKILLS MEMORY MESSAGE PRODUCTION SCRIPTS SPEECH FLUENCY AND SPEECH ERRORS

\section{REFERENCES AND SUGGESTED READINGS}

Greene, J. O. (1984). A cognitive approach to human communication: An action assembly theory. Communication Monographs, 51, 289-306.

Greene, J. O. (1997). A second generation action assembly theory. In J. O. Greene (ed.), Message production: Advances in communication theory. Mahwah, NJ: Lawrence Erlbaum, pp. 51-85.

Greene, J. O. \& Herbers, L. E. (2011). Conditions of interpersonal transcendence. International Journal of Listening, 25, 66-84.

\section{Advertisement Campaign Management}

\author{
ALI M. KANSO \\ University of Texas at San Antonio
}

The key to an effective advertising campaign is solid management. The process embodies a wide range of activities that may include brainstorming, consumer surveys, and media analysis. As a communication tool, advertising must consider the product type and factors affecting the sponsor's relationships with its publics. Managing the advertising campaign involves the following eight steps ( $\rightarrow$ Advertising Strategies):

Conducting a Situation Analysis: The purpose is to provide a research foundation that can be used to establish objectives, specify strategies, and articulate tactics. The analysis encompasses the company, consumer, market, product, and competition.

Identifying Problems and Opportunities: This step involves a close look at the firm's prior and current marketing processes, its financial and organizational competencies, its actual or potential areas of profitability, and forces that threaten its growth.

Establishing Short-term and Long-term Objectives: Once the advertiser identifies opportunities, the next step is to establish clear, specific, singular, realistic, measurable, and time-bound objectives.

Determining the Advertising Appropriation and Budgeting: Advertisers weigh the relative importance of price, product, or brand before deciding how and where to allocate expenditures.

Developing a Creative Strategy: Major components include: definition of the key problem, description of the product, identification of the persons who are most likely to purchase the product, clarification of the competition, specification of the consumer benefits, articulation of the reasons that support the benefit claim, determination of the message tone, and formulation of a call for action.

Creating Messages: The creation of effective messages requires the use of keywords and other qualities. Advertisers work meticulously to produce well-targeted, thought provoking, involving, and rewarding messages.

Selecting Appropriate Media: Several decisions have to be made to: identify the target audience(s), select the geographic area, determine the desirable level of reach within a time period, specify the frequency of advertising messages, decide the timing and continuity of the campaign, and choose the media that offer the best match with the intended market.

Outlining a Plan to Measure the Outcome: Measuring the campaign effectiveness is a dynamic process that involves all stages of the campaign but each stage may require different techniques.

In conclusion, managing an advertising campaign is a challenge that entails many interrelated decisions and requires strategic thinking. Advertisers must have a radar system to continuously forecast the consumers' wants and needs.

See also: A ADVERTISING $>$ ADVERTISING EFFECTIVENESS $>$ ADVERTISING STRATEGIES STRATEGIC COMMUNICATION 


\section{SUGGESTED READING}

Avery, J. (2010). Advertising campaign planning: Developing an advertising campaign-based marketing plan, 4th edn. Chicago: Copy Workshop.

\section{Advertising}

TIM AMBLER

London Business School

Advertising has been defined as "any paid form of non personal communication about an organization, product, service, or idea by an identified sponsor" (Alexander 1965, 9). Advertising intrudes into our lives and is not always welcome. Some scholars suspect that we are being manipulated by dark arts. Today, an estimated US $\$ 500$ billion is spent worldwide on local, national, and international advertising.

\section{History}

Since the dawn of time, sellers have been seeking to attract attention and present their wares in ways that encourage sales. A contemporary classified ad for a second-hand bicycle is substantively the same as an ad for a Roman chariot 2,000 years ago. Media have changed, notably broadcast and digital, and our understanding of how ads work has changed, but advertising itself has changed much less. Advertising has always provided information, used emotional appeals to sell to us, and reminded us. But it used to be less pervasive than it is today because of the limited media and the limited number of goods then available for trading.

Advertising agencies have existed since at least the eighteenth century but their formal standing as experts dates from the mid-nineteenth century in developed markets and the late twentieth century in the late developers. The importance of small start-up agencies is as great as it ever was but globalization has also promoted mergers of the larger, more mature, agencies into perhaps half a dozen multinationals. This is significant because with classic packaged goods, or fastmoving consumer goods, advertisers have shifted budgets from advertising to promotions, but the slack has mostly been taken up by new advertisers such as financial services and government. As a share of world GDP, however, advertising appears to have grown (www.warc.com).

Measurement techniques have become more sophisticated partly in response to advertiser demands to see quantified results and partly as advertisers and their agencies have taken a more scientific approach to understanding how advertising works. Content has increased in variety with more entertainment and appeals to emotion but this has largely been driven by the wish to exploit new media. Perceptions of different advertising styles may be seen as evolutionary by those involved but the changes in style also reflect the fashion cycles that are necessary to maintain the appearance of novelty (McDonald \& Scott 2007).

\section{The Advertiser's Perspective}

In recent years, the brief from client to agency setting out requirements has been increasingly formalized. The briefing itself is an interactive process as the agency brings its own experience and negotiating skills, typically, to making the goals easier to achieve and the budget bigger. What should emerge from the process is a clear identification of the target market and the changes the advertising should achieve. The brief should not describe the means, i.e., what the ad should contain, but the end, i.e., challenge the agency with what the campaign should achieve.

Ads work in two stages: they change brand equity (what is in consumer heads) and brand equity, at a later date, changes consumer behavior. That may imply that the goals for the ad campaign should be set by changes in brand equity (intermediate) metrics and the budget made available in those terms. In practice few advertisers formalize brand equity measurement in that way. Furthermore the correlation between intermediate and behavioral metrics can be poor so clients typically prefer the latter, e.g., sales or penetration or profit, where advertising can measurably deliver those goals.

Media neutral planning (MNP; Saunders 2004) as well as $\rightarrow$ integrated marketing communications (IMC; Schultz 1993) share the idea that communications should be planned from the consumer's perspective. The target market should ultimately determine the relevant media both in terms of readership and in providing the appropriate context for the copy. Thus, media 
considerations are less driven by reach (how many people see it), frequency, or the cost per 1,000 readers (or viewers) than the relevance of the media and whether, in that context, the message is likely to work.

This leads to the question of how the ads might be expected to work. For a new product or brand, the primary aim is, typically, achieving awareness. Thereafter, advertising works mostly through two approaches, broadly classified as either active or central processing, involving argument and logic, or passive peripheral processing, which relies on cues ( $\rightarrow$ Elaboration Likelihood Model).

Pre-testing is a contentious topic. Predictiveness is dubious and ads are rarely pre-tested against the particular goals for the campaign. Post-campaign assessment, on the other hand, is not contentious in principle although there are various competing approaches. Post-campaign assessment usually takes the form of 'tracking, i.e., the key brand equity metrics are consistently monitored over time, for example, on a monthly basis (for a summary see White 2005).

\section{The Consumer's Perspective}

From as early as the first half of the nineteenth century, there has been public ambivalence toward advertising. It is seen as manipulative, intrusive, and seeking to persuade us to buy what we do not need (such as lottery tickets) or to buy what is bad for us (such as alcohol, tobacco, or fatty foods). Because brand leaders are typically more expensive than their private label equivalents, some argue that advertising causes us to pay more than we should.

On the other hand, advertising pays for the media we enjoy such as television, newspapers, and the Internet. Quite often we enjoy the ads themselves which enter into general parlance such as 'It does what it says on the tin'.

Finally we should note that the consumer's attitude towards advertising is driven by television advertising rather than all media (Jin \& Lutz 2013).

\section{The Social Perspective}

Opponents of advertising claim that it commercializes culture, undermines values, and leads to less happiness as society is reminded of what it cannot afford $(\rightarrow$ Commercialization: Impact on Media Content). Supporters argue that advertising merely mirrors society as it is. They see it as a necessary part of a healthy market and contend that it has contributed to the growth of GDP and widespread prosperity (O'Guinn \& Faber 1991).

Advertising in itself is neither good nor bad, but it can be good or bad in the way it is used. Accordingly, most countries have developed regulation as a means to control 'bad', or potentially harmful, advertising while allowing 'good' advertising a reasonably free rein. Regulation, much of it self-regulation, has grown rapidly since the 1960s to meet increasing cultural sensitivities but also to dissuade governments from interfering. Self-regulation is seen as being more flexible and responsive to consumer protection than legal rules, but governmental wish to control the industry has led to 'co-regulation,' i.e., government retaining the right to intervene when they deem it necessary.

\section{See also: ADVERTISEMENT CAMPAIGN MANAGEMENT $>$ ADVERTISING EFFECTIVENESS \\ ADVERTISING EFFECTIVENESS, MEASUREMENT OF \\ ADVERTISING LAW AND REGULATION \\ ADVERTISING STRATEGIES $>$ BRANDS \\ COMMERCIALIZATION: IMPACT ON MEDIA CONTENT \\ ELABORATION LIKELIHOOD MODEL \\ INTEGRATED MARKETING COMMUNICATIONS}

\section{REFERENCES AND SUGGESTED READINGS}

Alexander, R. S. (ed.) (1965). Marketing definitions. Chicago: American Marketing Organization.

Ambler, T. \& Roberts, J. H. (2006). Beware the silver metric: Marketing performance measurement has to be multidimensional. Marketing Science Institute, Report 06-113. Cambridge, MA: Marketing Science Institute.

Jin, H. S. \& Lutz, R. J. (2013). The Typicality and Accessibility of Consumer Attitudes Toward Television Advertising: Implications for the Measurement of Attitudes Toward Advertising in General. Journal of Advertising 42(4), 343-357.

McDonald, C. \& Scott, J. (2007). Brief history of advertising. In G. J. Tellis \& T. Ambler (eds.), The Sage handbook of advertising. Thousand Oaks, CA: Sage. 
Nerlove, M. \& Arrow, K. (1962). Optimal advertising policy under dynamic conditions. Economica, 29, May, 129-142.

O’Guinn, T. C. \& Faber, R. J. (1991). Mass communication theory and research. In H. H. Kassarjian \& T. S. Robertson (eds.), Handbook of consumer behavior theory and research. Englewood Cliffs, NJ: PrenticeHall, pp. 349-400.

Saunders, J. (2004). Communications challenge: A practical guide to media neutral planning. London: Account Planning Group.

Schultz, D. E. (1993). Integrated marketing communications: Maybe definition is in the point of view. Marketing News, January 18, 17.

White, R. (2005). Tracking ads and communications. Admap, 460, 12-15.

\section{Advertising, Cross-Cultural}

HOLGER ROSCHK

Catholic University of Eichstaett-Ingolstadt

\section{KATJA GELBRICH}

Catholic University of Eichstaett-Ingolstadt

\section{MARTIN EISEND}

European University Viadrina in Frankfurt (Oder)

With the globalization of markets, advertising professionals are faced with the question whether to standardize their message internationally or to tailor it to each country's target culture. Culture can be seen as the values shared by the members of a society ( $\rightarrow$ Culture: Definitions and Concepts). Adapting the message to the target audience enables companies to conform with cultural values, while standardizing entails the risk of violation of cultural rules. Theories such as learning theories and related empirical findings suggest that advertising is most persuasive if it conforms to recipients' values (e.g., Teng \& Laroche 2006). Further, results of a contemporary cross-cultural meta-analysis for gender stereotyping show that sex role portrayal in advertising reflects past gender-related value changes in society (Eisend 2010; $\rightarrow$ Sex Role Stereotypes in the Media). In other words, advertising is (or should be) a mirror of society and the culture it is directed toward. Culture interferes with advertising in various ways. It impacts advertising objectives, message appeals, sex role portrayal, and humor.
Advertising objectives such as attracting attention or increasing purchase intention need to be adapted to the culture-specific communication style. In high-context societies such as Japan, little is explicitly stated and communication relies more on contextual cues, whereas in low-context cultures like the US, direct communication is favored. Accordingly, advertising is less persuasive in Japan than in the US. It aims at anchoring a product in the recipient's mind rather than at direct trial.

The goal of appealing to values like adventure or freedom is to condition a product or service in such a way that the audience associates it with these values. Extensive content-analytic research on advertising campaigns across cultures indicates that the values stressed tend to correspond to the countries' societal values, although economic and political transitions may be responsible for some contradictory results. For instance, in cultures such as Russia or Mexico, where individuals accept that power is distributed unequally, advertising appeals to status symbols more often than in egalitarian cultures like the US. Advertisements reflect self-achievement more often in individualistic cultures like France, in which individuals see themselves as detached from others, compared to collectivistic cultures like China, in which individuals' identity is stronger linked to their social network. The opposite holds true for sociability.

Sex roles are learned during the socialization process and differ across cultures. In masculine societies like Japan, sex roles are distinct and stronger gender stereotyping in advertising can be observed compared to feminine cultures like Sweden, where sex roles overlap. However, these results are relative. For instance, even in feminine cultures, more men than women appear in professional situations, while women are more often portrayed in non-job activities. Thus, gender stereotyping is prevalent across cultures, though it has decreased over the years mainly due to developments in high-masculinity countries (Eisend 2010).

Humor plays a vital role in message creation. It is a subversive play with conventions, norms, or ideas of a society, which comes in forms such as puns, jokes, irony, or satire. Since nonmembers of the society usually do not know those conventions they cannot understand the advertisement. Hence, 
humor is unlikely to travel across cultures. Failed humor can even confuse or offend the audience.

Advertising may also break with societal rules. There is ample anecdotal evidence for campaigns, which on purpose or accidentally violate cultural values, for instance, by depicting unfavorable sex roles. The Italian clothing company Benetton is a prominent example for its offensive campaigns. Shock advertisements, depicting, for example, a black woman as a wet nurse, and an unwashed newborn baby with the umbilical cord still attached, gave rise not only to public criticism, but also to consumer movements boycotting the company's products.

However, when most advertisers stick to traditional values there are various motives for breaking with them. Nonconforming advertisements may be successful as they gain attention through originality, fulfill the need for novelty seeking, or appeal to transnational target groups, who want to distinguish themselves from their own culture. Further, these advertisements may target values which are desired by a society, but are not practiced. For instance, New Zealand and Sweden are rather individualistic countries with regard to the way that people act, but people in both countries seek more collectivism. Breaking with cultural rules also allows companies to intentionally position themselves as foreign.

\section{See also: $>$ ADVERTISING $>$ ADVERTISING EFFECTIVENESS, MEASUREMENT OF \\ D ADVERTISING STRATEgIES CULTURE: DEFINITIONS AND CONCEPTS SEX ROLE STEREOTYPES IN THE MEDIA}

\section{REFERENCES AND SUGGESTED READINGS}

De Mooij, M. K. (2013). Global marketing and advertising: Understanding cultural paradoxes, 4 th edn. Thousand Oaks, CA: Sage.

Eisend, M. (2010). A meta-analysis of gender roles in advertising. Journal of the Academy of Marketing Science, 38(4), 418-440.

Müller, S. \& Gelbrich, K. (2014). Interkulturelles marketing [Cross-cultural marketing], 2nd edn. Munich: Vahlen.

Teng, L. \& Laroche, M. (2006). Interactive effects of appeals, arguments, and competition across North American and Chinese cultures. Journal of International Marketing, 14(4), 110-128.

\section{Advertising, Economics of}

MATTHEW P. MCALLISTER

Pennsylvania State University

The economics of $\rightarrow$ advertising shape the history, current state, and future of media. Advertising revenue influences media not just through the insertion of ads, but also its nonadvertising content and access.

By 1900 both the US newspaper and magazine industries generated most of their revenue from advertising. Readers went from being primarily revenue providers - the customer/market of media - to being the commodity sold to the media's larger customer, advertisers. For-profit broadcasting was nearly completely dependent upon advertising. Other media carry only advertising and promotional messages, including billboards, direct mail, and branded websites. The advertising industry involves three powerful groups: advertisers, advertising agencies, and media. The largest advertisers are multinational conglomerates such as Procter and Gamble, spending billions annually. The US receives the most advertising spending, with China a rapidly growing second. Agencies engage in creative, research, $\rightarrow$ media planning and buying. Large global holding companies such as Omnicom own multiple full-service agencies that integrate marketing, advertising, and public relations functions, and leverage their market share in negotiations with media companies.

Advocates contend that advertising encourages lower prices through economies of scale, economic growth, and 'free' media. Criticisms include the barrier to entry for new commodities, and incentives for the growth of large media monopolies. Advertising also suppresses criticism of the industry and encourages pro-consumption messages in media content. Some media audiences are more valuable than others: audiences with disposable income and a susceptibility to advertising may find many content options.

Changes in advertising spending affect media viability. Decreasing advertising revenue for newspapers triggered concern about the future of $\rightarrow$ journalism. Digital's interactivity and convergence have attracted advertising spending and facilitated behavioral measures such as 'costper-click.' The resulting emphasis on data mining 
has turned media companies into audienceinformation brokers that collect audiences' media use and consumption patterns ( $\rightarrow$ Exposure to Communication Content).

Branded entertainment, where advertisers involved in the production processes and integrate the selling function in traditionally autonomous genres, also changes the economic conventional wisdom of advertising.

\section{See also: ADVERTISING ADVERTISING, HISTORY OF BRANDS D COMMERCIALIZATION: IMPACT ON MEDIA CONTENT COMMODIFICATION OF THE MEDIA CONCENTRATION IN MEDIA SYSTEMS CONSUMER CULTURE CONSUMERS IN MEDIA MARKETS $>$ EXPOSURE TO COMMUNICATION CONTENT D EXPOSURE TO THE INTERNET GLOBALIZATION OF THE MEDIA $\checkmark$ JOURNALISM MEDIA CONGLOMERATES MEDIA ECONOMICS MEDIA PLANNING}

\section{REFERENCES AND SUGGESTED READINGS}

Baker, C. E. (1994). Advertising and a democratic press. Princeton, NJ: Princeton University Press.

Sinclair, J. (2012). Advertising, the media, and globalization: A world in motion. London: Routledge.

Turow, J. (2011). The Daily You: How the new advertising industry is defining your identity and your worth. New Haven, CT: Yale University Press.

\section{Advertising Effectiveness}

GERARD J. TELLIS

University of Southern California

By the term 'advertising effectiveness', we mean what changes $\rightarrow$ advertising creates in markets. Beyond changes in markets, advertising also creates changes in consumers' awareness, $\rightarrow$ attitudes, beliefs, and intentions. In the interest of focus and parsimony, this entry concentrates on the effects of advertising only on market behavior. This topic has been the subject of research from the time firms began to advertise, over a hundred years ago. Scientific research has begun to accumulate especially in the last 50 years (Tellis 2004; Tellis \& Ambler 2007). This research falls within one of two paradigms: behavioral research and econometric research. Behavioral research uses theater or laboratory experiments to address the effects of advertising on awareness, attitudes, beliefs, and intentions ( $\rightarrow$ Experiment, Laboratory). On the other hand, field research uses field experiments ( $\rightarrow$ Experiment, Field) and econometric models to assess the effects of advertising on market behavior. We can classify field research into three groups: contemporaneous effects of ad intensity, dynamic effects of ad intensity, and effects of ad content. These subjects are the focus of the next three sections.

\section{Contemporaneous Effects of Ad Intensity}

Weight studies examine the effect of differences in ad budget across time periods or regions on sales. The main focus of such studies is to determine whether an increase in budget translates into a proportional or profitable increase in sales of the advertised product. Research leads to the following four important and surprising findings. First, changes in weight alone do not cause dramatic or substantive changes in sales. Second, prolonged cessation of advertising sometimes leads to deleterious effects on sales. Third, if advertising is effective, its effects are visible early on in the life of a campaign. Fourth, changes in media used, content of the ad, product advertised, target segments, or scheduling of ads are more likely to cause changes in sales than are changes in weight alone. These results have three implications. First, firms could be over-advertising; as a result, cutbacks in advertising do not lead to a loss in sales. Second, advertising may have delayed or even permanent effects, so that continued advertising at the same level is not always necessary. Third, a firm's budget increase or original budget itself may be more fruitfully employed in changes in media, content, target segments, product, or schedule rather than in weight alone.

Research on advertising elasticity, i.e. the percentage change in sales for a 1 percent change in the level of advertising, leads to the following important findings. First, across all studies, the mean estimated advertising elasticity is about 0.1 , i.e., about one-twentieth the corresponding price elasticity. Second, advertising elasticity has been declining over time. Third, advertising elasticity is higher in earlier than later stages of the product 
life cycle, and for durables than non-durables. Fourth, advertising elasticities are higher for aggregate data than for disaggregate data, probably due to data-aggregation bias. These results suggest that price discounting may lead to a greater increase in sales than does an advertising increase; however, whether that increase is profitable would depend on the level of price cut, which consumers use it, and how much of that gets to the ultimate consumer rather than being pocketed by distributors. They also suggest that advertising may be more profitable for new products, while price discounting may be more profitable for mature products.

Research on advertising frequency leads to the following five findings. First, the effects of advertising exposure are less prominent and immediate and more fragile than those of price or promotion on brand choice. Second, in general, increasing frequency of exposures increases probability of brand choice at a decreasing rate. Third, for mature, frequently purchased products, the optimum level of exposure may be relatively small, ranging from one to three exposures a week. Fourth, brand loyalty may moderate response to ad exposures, in that established brands have an earlier and lower peak response to ad exposures than newer brands. Fifth, brand choice may be more responsive to the number of consumers the ad reaches than to the frequency with which it is repeated. These results suggest, among other things, that advertisers need to target loyal and nonbuyers of their products with different levels of exposures.

\section{Dynamic Effects of Ad Intensity}

The carryover effect of advertising is that effect it has on sales beyond the moment or time of exposure. Econometric studies have typically estimated the size and duration of the carryover effect. Research leads to the following main findings. First, advertising typically has some carryover, so that all its effectiveness does not occur in the contemporaneous time period to its exposure to the consumer. Second, the estimated effect of advertising depends on the level of data aggregation. Estimated carryover effects tend to be longer with the use of more aggregate data. In general, the more disaggregate the time period of data, the less biased is the estimated effect of advertising carryover. Further, the effect of advertising may last for fairly short periods - hours, days, or weeks - rather than for long periods such as months or years. Third, advertising's effects vary by region, city, and time of the day. Fourth, the carryover effect of advertising is as large as its current or instantaneous effect. These findings suggest, first, that advertisers should neither assume their advertising has only contemporaneous effects nor assume that is has very long-term carryover; second, advertisers need to evaluate the carryover effect of their advertising and do so with as temporally disaggregate data as they can find or collect; third, advertisers need to analyze effects by region and time period rather than rely on simple generalizations.

Ad campaigns wear out if run long enough. Wear-out occurs more slowly for ad content that is complex, emotional, or ambiguous, for ads that are less rather than more effective, for infrequently rather than frequently purchased products, for exposures spread apart rather than clustered together, for light rather than heavy viewers of TV, and for campaigns with increasing variety of ads or ad content. A break in a campaign may lead to an increase in effectiveness of the ad; if that happens, the ad wears out even faster than it did the first time around. In rare cases, possibly for new products, advertising seems to have permanent effects. That is, the effect of advertising persists even after the advertising is withdrawn. One of the implications of these findings for advertisers is that an ad which is ineffective early on should be discontinued. Also, whenever resources and time permit, advertisers should test their ads for wear-in and wearout and accordingly decide on the duration of the ad campaign.

\section{Effects of Ad Content}

Research on ad content seems to suggest the following preliminary findings. First, changes in the creative, medium, target segment, or product itself sometimes lead to changes in sales, even though increases in the level of advertising by itself does not. Second, informative appeals may be more important early rather than late in the product's life cycle. Conversely, emotional appeals 
may be more effective late rather than early in a product's life cycle. These findings have two important implications for advertisers. First, to increase effectiveness, advertisers should modify content more than increase weight or frequency. Second, advertisers need to test and typically vary the content of their advertising with the life stage of the product.

\section{See also: $>$ ADVERTISEMENT CAMPAIGN \\ MANAGEMENT \ADVERTISING ADVERTISING EFFECTIVENESS, MEASUREMENT OF \\ ADVERTISING STRATEGIES $>$ ATTITUDES \\ BRANDS D EXPERIMENT, FIELD DEXERIMENT, LABORATORY $>$ QUANTITATIVE METHODOLOGY}

\section{REFERENCES AND SUGGESTED READINGS}

Eisend, M., Langner, T., \& Okazaki, S. (2012). Advances in advertising research. vol. III: Current insights and future trends. Wiesbaden: Springer Verlag.

Rosengren, S., Dahlen, M., \& Okazaki, S. (2013). Advances in advertising research. vol. IV: The changing roles of advertising. Wiesbaden: Springer Gabler.

Tellis, G. J. (2004). Effective advertising: How, when, and why advertising works. Thousand Oaks, CA: Sage.

Tellis, G. J. \& Ambler, T. (eds.) (2007). The Sage handbook of advertising. Thousand Oaks, CA: Sage.

\section{Advertising Effectiveness, Measurement of}

FRED BRONNER

University of Amsterdam

Nowadays there is little argument in the commercial as well as academic world that campaigns should be monitored to manage them better in the marketplace (Advertisement Campaign Management). Which research design is adequate for measuring ad effect and which key performance indicators, divided into advertising response and brand response, have to be selected?

Answering questions about the effect of a campaign upon variables like brand awareness, brand sympathy, or brand usage, and isolating the net effect of an advertising campaign on changes requires an appropriate research design. When we combine two designs (pre-campaign/ post-campaign and exposed / non-exposed) we obtain a very powerful tool. The campaign effect score $E$ equals $(a-b)-(c-d)$. The element $(a-b)$ can be considered as an indicator of the effect of developments taking place in the world that are not due to the campaign - the element $(c-d)$ represents the changes that take place separately from the campaign. Hence, we can separate campaign influence from other factors such as high levels of media attention ( $\rightarrow$ Experiment, Field; Experiment, Laboratory).

$\begin{array}{lll} & \text { Before } & \text { After } \\ \text { Exposed } & b & a \\ \text { Not Exposed } & d & c\end{array}$

The most difficult challenge in this scheme is how to establish whether someone has been exposed to the campaign or not. The solution is the use of panels ( $\rightarrow$ Survey). In the combined panel/ad hoc design a pre-measurement is carried out on sample $X$. After the campaign this sample is subjected to a limited re-interview, exclusively to establish if they were exposed to the campaign or not. These exposure scores are added to the premeasurement. An independent post-measurement is carried out on sample $Y$ in which both exposure and effect variables are measured.

Daniel Starch wrote as long ago as 1923 that for an advertisement to be successful it must be seen, read, believed, remembered, and acted upon. In the Starch philosophy, and still today, an advertisement must first be seen. How can we measure accurately if a consumer has seen an ad (cognitive response)? In the research world there are two schools of thought on this: measure spontaneously, or show the TV commercial or print ad and ask if the consumer has seen it (recognition). Because visual prompts connect with memory traces more effectively than verbal prompts it is better to use recognition.

For affective ad response in a standardized approach, one set of beliefs about ads is used to compare strong and weak points of the ads over all beliefs. For conative ad response behavioral measures can be used. Nowadays, many print ads and TV commercials include in a lead to an Internet site. Post hoc qualitative research on site visitors can reveal much about the advertisement's role. 
In nearly all effect studies, the effect of advertising upon brand awareness (cognitive brand response) is measured in three steps: top of mind ("Which beer brands do you know?" - first one mentioned), spontaneous ("Which beer brands do you know?" all brands mentioned), and aided ("Here is a list of beer brands with their logos. Which ones do you know, at least by name?"). Familiarity can also be measured, and is a more nuanced scale ("just heard of / know just a little / know fair amount / know very well"; $\rightarrow$ Memory; Information Processing). For the measurement of affective brand response the brand that is the focus of the campaign and its main competitors are measured on a salient list of attributes (brand beliefs) relating to corporate-, product-, and user-profile facets. Finally, likely changes in behavior (conative brand response) are measured through the introduction of such measures as purchase consideration and intention. Advertising can influence future buying decisions even when subjects do not recollect ever having seen the ad. Neuro-marketing may shed more light on this phenomenon in future years.

Increasing simultaneous media exposure raises questions on how media advertising should be planned and measured in the near future. The use of multimedia and cross-media strategies will influence the measurement of advertising effectiveness.

\section{See also: ADVERTISEMENT CAMPAIGN \\ MANAGEMENT DADVERTISING EFFECTIVENESS \\ ADVERTISING STRATEGIES D EXPERIMENT, FIELD \\ $>$ EXPERIMENT, LABORATORY INFORMATION \\ PROCESSING $>$ MEMORY $>$ SURVEY}

\section{REFERENCES AND SUGGESTED READINGS}

Bronner, A. E. \& Neijens, P. (2006). Audience experiences of media context and embedded advertising: A comparison of eight media. International Journal of Market Research, 48(1), 81-100.

Eisend, M., Langner, T., \& Okazaki, S. (2012). Advances in Advertising Research (vol. III): current insights and future trends. Wiesbaden: Springer Verlag.

Rosengren, S., Dahlen, M., \& Okazaki, S. (2013). Advances in advertising research (vol. IV): the changing roles of advertising. Wiesbaden: Springer Gabler.

Starch, D. (1923). Principles of advertising. Chicago: A.W. Shaw.

\section{Advertising: Global Industry}

JOHN SINCLAIR

University of Melbourne

Advertising is the key link in the mutually sustained global expansion of consumer goods and services industries and the media of communication that carry their commercial messages ( $\rightarrow$ Advertising). It is the life-blood of the media, the motive force behind media industry development, and the publicly most visible dimension of $\rightarrow$ marketing.

The period since World War II has seen the internationalization of the advertising industry proceed in tandem with the emergence of the 'multinational,' now global, consumer goods corporation, as well as with the international expansion of new media, driven by their capacity to carry commercial messages to audiences ( $\rightarrow$ Globalization of the Media). The flow of advertising expenditure toward new media, notably subscription television and, more dramatically, the Internet, is undercutting the 'mass' media we have known in the past.

An accompanying drift to nonadvertising forms of promotion is tending to undermine the traditional business model on which the relationship between advertisers and the media has rested since the advent of commercial broadcasting. Instead of the media amassing audiences for sale to advertisers, the trend is propelling growth in new means of marketing delivery, particularly the mobile phone, the Internet, and interactive TV. This implies on the one hand a more fragmented society, but on the other, a more interactive relationship between producersand consumers ( $\rightarrow$ AudienceSegmentation).

Recent theory and research have largely moved away from the study of advertising as such, and more toward consumer culture in general. In the process, there is also a useful fusion being achieved between the traditionally antagonistic camps of political economy and $\rightarrow$ cultural studies, under the rubric of "cultural economy" (McFall 2004), while some of the most innovative work in recent years has focused on brands and branding (Arvidsson 2006).

See also: $>$ ADVERTISING $>$ ADVERTISING, CROSS-CULTURAL $>$ ADVERTISING, ECONOMICS OF 
AUDIENCE SEGMENTATION $>$ BRANDING

BRANDS CABLE TELEVISION CONSUMER

CULTURE CULTURAL STUDIES

GLOBALIZATION OF THE MEDIA M MARKETING

POLITICAL ECONOMY OF THE MEDIA

PUBLIC RELATIONS SATELLITE TELEVISION

\section{REFERENCES AND SUGGESTED READINGS}

Arvidsson, A. (2006). Brands: Meaning and value in media culture. London: Routledge.

McFall, L. (2004). Advertising: A cultural economy. London: Sage.

Sinclair, J. (2012). Advertising, the media and globalisation. London: Routledge.

\section{Advertising, History of}

LIZ MCFALL

Open University

The modern sense of $\rightarrow$ advertising can be traced to its origins in late-sixteenth century attempts to establish information bureaus. Theophraste Renaudot established the Bureau d'adresse et de rencontre in France in 1630 and published one of the first advertising newspapers. Similar offices and newspapers soon formed across Europe. By the 1750s, advertising newspapers proliferated in forms ranging from the state monopoly Intelligenzblatt in Prussia to the mixed economy of newspapers in England. The office function was superseded by the growing network of coffee houses ( $\rightarrow$ Public Opinion). Coffee houses played a role in the development of financial institutions acting as travel agents, insurance agents, hotels and 'conference centers.' Their main connection, however, was to the press and advertising. The earliest coffee houses distributed newspapers and acted as reading rooms ( $\rightarrow$ Newspaper, History of).

The advertising agency system developed from these early connections to coffee houses and newspapers. The first British advertising agency was Tayler and Newton, established in 1786, followed by Whites in 1800 and in 1812 by Reynells, Lawson and Barker, and Deacons. Archive material shows agencies involved in the distribution of news and newspapers, political parliamentary correspondence, and advising on advertisement design and placement. Some agencies combined advertising trade with services such as bookselling, insurance, dentistry, and undertaking. By the early twentieth century, advertising agencies in a recognizable form dominated the institutional field, with agencies increasingly offering a range of services to clients or 'accounts' under the 'fullservice agency' model. Full-service was the term adopted by agencies which provided services including research and creative design, account management, and media space-buying. The fullservice model competed with agencies providing minimal service and offering low rates by 'commission splitting' or farming bulk-bought space. By the middle of the twentieth century, the advertising industry had largely settled into the full-service model.

Historians differ over the precise dates of the first printed advertisements. The word 'advertisement' appears in print in the sixteenth century and over press announcements in the seventeenth century. These were not really advertisements in the contemporary sense. Rather, the term was interchangeable with 'announcement' or 'notice. By the 1700 s 'advertisement' was deployed in some newspapers to refer to particular types of advertisement while other newspapers completely refused paid content. Newspapers had a vested interest in accepting advertisements but this vied with reservations, best illustrated by the regulations imposed upon advertisers. The 'agate-only' rule, for example, stipulated that paid advertisements must use only small, classified typefaces. Advertisers used numerous techniques to circumvent these regulations for instance by using drop capitals, repetition, and acrostics to produce patterns. Instead of newspapers, broadsheets and posters were often used to create visual displays. Poetry, jokes, puzzles, rhythm, association, endorsement, and emotional blackmail were also used as persuasive devices. Samuel Johnson's comment "the improper disposition of advertisements," by which "the noblest objects may be so associated as to be made ridiculous," reveals the long historical disapproval of such rhetorical excesses.

Throughout its history, advertising has used a range of media and technologies. From the 1830s, gas lanterns were used to illuminate posters and shops, by the 1870 s, magic lanterns displayed animated messages. Advertisements were placed on walls, windows, bridges, public transport, trees, barns, and cliff-faces. Poster sites were 
unregulated and competition was fierce. Placardbearers were extensively used. Costumed men, women, and children carried boards or dressed up as the object advertised. There were also forgotten contraptions like 'advertising vans.' These mobile horse-drawn devices came in a variety of shapes: globes, pyramids and mosques, and were complemented by stationary advertising devices that stood in busy thoroughfares. The atmosphere was summed up in The Times in 1892 "advertisements are turning England into a sordid and disorderly spectacle from sea to sea ... Fields and hillsides are being covered with unwonted crops of hoardings. The sky is defaced by unheavenly signs." Through such means nineteenth-century advertising messages pervaded both public and private, urban and rural environments.

\section{See also: $>$ ADVERTISING $>$ MEDIA HISTORY}

NEWSPAPER, HISTORY OF PUBLIC OPINION

\section{REFERENCES AND SUGGESTED READINGS}

Lears, J. (1994). Fables of abundance: A cultural history of advertising in America. New York: Basic Books.

Leiss, W., Kline, S., Jhally, S., \& Botterill, J. (2005). Social communication in advertising, 3rd edn. London: Routledge.

McFall, L. (2004). Advertising: A cultural economy. Thousand Oaks, CA: Sage.

Pope, D. (1983). The making of modern advertising. New York: Basic Books.

Presbrey, F. (1929). The history and development of advertising. New York: Greenwood.

\section{Advertising Law and Regulations}

SOONTAE AN

Ewha Womans University

The role of $\rightarrow$ advertising in society continues to expand around the world. In response, many societies face greater challenges in regulating advertising to protect the public from deceptive and unfair business conduct. Although the scope of advertising law and regulations varies from country to country, regulation is generally manifested as self-regulation by the industry and statutory regulation by various government bodies.
In many countries, self-regulation - voluntary, industry-wide control by advertisers - complements legal regulatory systems. Given that each self-regulatory system offers a different set of standards and codes, the International Chamber of Commerce (ICC) plays an important role in coordinating efforts to develop international guidelines and policies. The ICC publishes the International Code of Advertising Practice that is used and integrated into many self-regulatory systems around the world and handles complaints when the scope of a dispute spans multiple countries, or in cases where national self-regulatory systems do not exist. Other key international organizations include the International Advertising Association (IAA) and the World Federation of Advertisers.

With statutory regulation, a variety of judicial tools can be utilized to achieve prompt and efficient control of advertising practices. Depending on the nature and type of advertising, many different specialized government agencies oversee its regulation. For a long time, advertising was considered to be outside the realm of freedom of expression. When the US Supreme Court first considered the issue in 1942, it decided that "purely commercial advertising" was not the type of speech protected by the First Amendment. In 1976 , that decision was explicitly overruled by the US Supreme Court, who reasoned that such advertisements conveyed vital information to the public and that a free enterprise economy depended upon a free flow of commercial information. Contrary to the US Supreme Court's categorical approach, the European courts have tended to apply the same principles to both commercial and non-commercial expression of speech.

Advertising of certain products or services has received closer regulatory scrutiny. For example, the issue of advertising toward children has prompted many restrictions. Furthermore, advertising of certain products is prohibited, especially on broadcast media. Direct-to-consumer prescription advertising is forbidden in all countries except in the US and New Zealand. In fact, advertising of cigarettes demonstrates a substantially different application of the commercial speech doctrine. Unlike the US and Canada, many European countries have imposed a comprehensive ban on tobacco advertising . 
See also: A ADVERTISING F FEEDOM OF COMMUNICATION F FREDOM OF THE PRESS, CONCEPT OF $>$ SELF-REGULATION OF THE MEDIA

\section{REFERENCES AND SUGGESTED READINGS}

Boddewyn, J. J. (1992). Global perspectives on advertising self-regulation: Principles and practices in thirty eight countries. Westport, CT: Quorum Books.

Shaver, M. A. \& An, S. (2013). The Global Advertising Regulation Handbook Armonk, NY: M.E. Sharpe.

Shiner, R. A. (2003). Freedom of Commercial Expression. Oxford: Oxford University Press.

\section{Advertising as Persuasion}

BOB M. FENNIS

University of Groningen

Advertising as $\rightarrow$ persuasion may be defined as intentional, commercial communication aimed at convincing consumers of the value of the product or brand advertised. It focuses on the impact of advertising stimuli on cognitive, affective, and behavioral consumer responses (Fennis \& Stroebe 2010). As a classic approach, the so called "Yale studies" (Hovland, Janis, \& Kelley 1953; $\rightarrow$ Media Effects, History of) produced the messagelearning approach to persuasion stating that persuasion involves a four-stage process: attention, comprehension, yielding, and retention. Hence, persuasive ads are those that are attentiongrabbing, easy to comprehend, convincing, and memorable (see Fennis \& Stroebe 2010).

The $\rightarrow$ elaboration likelihood model (ELM; Petty \& Cacioppo 1986) and the heuristic systematic processing model (HSM; Chaiken 1980) represent more contemporary approaches and assume that persuasion is a function of two distinct modes of processing that anchor a controlled-automatic continuum. When consumer motivation and/or ability are high, persuasion is the result of careful scrutiny of the true merits of the product that is advertised in the message. In contrast, when motivation and/or ability is low, persuasion comes about via less effortful means, with consumers basing their evaluations on message elements that offer shortcuts for inferring something about product quality.

While these frameworks rely on conscious information processing to understand persuasion effects, recent developments have centered on studying unconscious influences of advertising spurred, by work on automatic construct activation (i.e., 'priming'; Bargh 2002).

\section{See also: ADVERTISING ADVERTISING EFFECTIVENESS, MEASUREMENT OF \\ ATTENDING TO THE MASS MEDIA \\ ATTITUDE-BEHAVIOR CONSISTENCY \\ ELABORATION LIKELIHOOD MODEL \\ INFORMATION PROCESSING $>$ MEDIA \\ EFFECTS, HISTORY OF $>$ PERSUASION}

\section{REFERENCES AND SUGGESTED READINGS}

Bargh, J. A. (2002). Losing consciousness: Automatic influences on consumer judgment, behavior, and motivation. Journal of Consumer Research, 29, 280-285.

Chaiken, S. (1980). Heuristic versus systematic information processing and the use of source versus message cues in persuasion. Journal of Personality and Social Psychology, 39, 752-766.

Fennis, B. M., \& Stroebe, W. (2010). The psychology of advertising. Hove, UK: Psychology Press.

Hovland, C. I., Janis, I. L., \& Kelley, H. H. (1953). Communication and persuasion: Psychological studies of opinion change. New Haven, CT: Yale University Press.

Petty, R. E. \& Cacioppo, J. T. (1986). Communication and persuasion: Central and peripheral routes to attitude change. New York: Springer.

\section{Advertising: Responses across the Life-Span}

\author{
MONIEK BUIJZEN \\ Radboud University Nijmegen
}

Advertising responses are thoughts, emotions, and behaviors generated by exposure to commercial messages. Responses to $\rightarrow$ advertising can be divided into cognitive, affective, and behavioral responses. Cognitive responses include recall or recognition of advertisements and brands, affective responses include likes and dislikes of advertisements and brands, and behavioral responses involve purchasing and consuming the advertised brands ( $\rightarrow$ Advertising Effectiveness; Advertising Effectiveness, Measurement of).

Advertising research has shown that the way consumers respond to persuasive information 
varies greatly across different stages of life (John 1999). In particular, children are more receptive to persuasive information than adults, because they have less experience with it. Compared to adults, children are less able to come up with critical thoughts and counterarguments while being exposed to advertising.

During childhood and adolescence $(\rightarrow$ Development Communication), children develop various advertising-related competencies, which are known as "advertising literacy" (Rozendaal et al. 2011; $\rightarrow$ Media Literacy). Seven competencies have been identified: (1) distinguishing commercials from programs, (2) recognition of advertising's source, (3) perception of the intended audience, (4) understanding advertising's selling intent, (5) understanding advertising's persuasive intent, (6) understanding of advertising tactics and appeals, (7) recognizing bias in advertising.

In addition to these conceptual advertising competencies, recent literature assumes that the development of advertising literacy is not only a matter of obtaining the necessary advertising knowledge, but also of acquiring the informationprocessing skills to apply that advertising knowledge while processing an advertisement $(\rightarrow$ Information Processing). Due to the affectbased nature of contemporary advertising, in combination with children's immature cognitive abilities, children primarily process advertising under conditions of low elaboration $(\rightarrow$ Elaboration Likelihood Model) and, consequently, are unlikely to apply conceptual advertising knowledge as a defense (Buijzen, Van Reijmersdal, \& Owen 2010). Therefore, current conceptualizations of advertising literacy include three dimensions: conceptual advertising literacy, including the seven competencies, advertising literacy performance, involving the actual use of conceptual advertising knowledge, and attitudinal advertising literacy, including loweffort affective mechanisms, functioning as a defense under conditions of low elaboration.

As yet, advertising research has predominantly focused on the development of conceptual advertising literacy. Although it is assumed that advertising literacy performance and attitudinal advertising literacy emerge later in the developmental sequence, it is unclear at what stage. Moreover, there is a lack of knowledge on the differential impact of the three dimensions on the cognitive, affective, and behavioral responses to advertising.
To gain full understanding of advertising responses across the life-span, future research should recognize the conceptual complexity of both advertising responses and advertising literacy.

\section{See also: A ADVERTISING \ADVERTISING \\ EFFECTIVENESS \ADVERTISING EFFECTIVENESS, MEASUREMENT OF ADVERTISING STRATEGIES \\ DEVELOPMENT COMMUNICATION \\ ELABORATION LIKELIHOOD MODEL \\ INFORMATION PROCESSING MEDIA LITERACY}

\section{REFERENCES AND SUGGESTED READINGS}

Buijzen, M., Van Reijmersdal, E. A., \& Owen, L.H. (2010). Introducing the PCMC model: An investigative framework for young people's processing of commercial media content. Communication Theory, 20, 427-450.

John, D. R. (1999). Consumer socialization of children: A retrospective look at twenty-five years of research. Journal of Consumer Research, 26, 183-213.

Rozendaal, E., Lapierre, M., Buijzen, M., \& Van Reijmersdal, E. A. (2011). Reconsidering advertising literacy as a defense against advertising effects. Media Psychology, 14, 333-354.

\section{Advertising Strategies}

BAS VAN DEN PUTTE

University of Amsterdam

Advertising strategy is the set of decisions an organization takes with respect to the employment of $\rightarrow$ advertising to reach one or more objectives among a specific target group. Each advertising strategy is based on the marketing strategy that encompasses the strategic decisions regarding all marketing activities, such as packaging, price, distribution, and promotion ( $\rightarrow$ Marketing). Within this set of marketing activities, advertising is part of the promotion strategy. Besides defining target group and communication objectives, main parts of the advertising strategy are message strategy and $\rightarrow$ media planning strategy. A further difference can be drawn between message strategy and creative execution strategy. The message strategy determines what communication objective is addressed by an advertisement; the creative execution defines 
how this objective is addressed. Though the ultimate goal of advertising is to maintain and increase the level of brand sales, most often advertising is employed to reach intermediate goals. Most important of these is communicating how a brand is positioned among its competitors. Other often-employed intermediate goals are brand awareness, generating a general positive feeling toward the brand, and purchase intention.

An important question is how the most effective message strategy can be selected. Generally it is advised, besides maintaining and increasing brand awareness, that the advertising strategy should match the main purchase motives of consumers. Many overviews of message strategies have been published and there is no generally agreed-upon typology. Nevertheless, a central element of most typologies is the difference between informational advertising that appeals to the rational mind and emotional advertising that appeals to the feelings of consumers ( $\rightarrow$ Cognitive Science).

An example is the well-known FCB grid which consists of four quadrants, defined by two dimensions: level of involvement and a thinking-feeling dimension. In the thinking dimension, often an important consumer motive is to solve a practical problem. In the high-involvement/thinking quadrant, the purchase is important to consumers and they make a rational decision based on functional information. Therefore, in this situation an informational message strategy should be used. In the low-involvement/thinking quadrant, buying behavior is habitual and consumers want to spend as little time and brain activity as possible on purchasing products, often fast-moving consumer goods. The primary aim of advertising is to remind consumers of the existence of the $\rightarrow$ brand. In the high-involvement/feeling quadrant, the consumer motive is ego gratification, that is, the need to defend, enhance, and express one's basic personality. The advice is to apply a message strategy that aims at relating the brand to the personality of the consumer. The low-involvement/feeling quadrant is reserved for products where involvement is low and the purchase decision is based on sensory gratification, that is, the desire to please one or more of the five senses. The message strategy should stress how the brand stimulates personal satisfaction, and advertising should induce product trial so people can experience the brand. Finally, social acceptance can be relevant in situations of both low and high involvement. The message strategy can address the need to be viewed favorably in the eyes of others.

Once the main message strategy is chosen, campaign developers can choose from a long list of creative execution strategies. How many product advantages should be mentioned, and should the best argument be mentioned first or last? Should the information be one- or two-sided? Should the conclusion be explicit or implicit? Should an endorser be employed and, if so, should this be a celebrity, expert, consumer, attractive or erotic model, or perhaps an animated character? Should the format be a testimonial, demonstration, product comparison, slice of life, or dramatization? Should humor be used, or fear? Unfortunately, there are no easy answers to these and many other questions. A particular executional factor may be highly effective in one advertising campaign, but may cause detrimental results in another campaign. The effectiveness of each executional factor is dependent on many variables, primarily the chosen advertising objective, the product category, and the motives and personal characteristics of the target group.

See also: $>$ ADVERTISEMENT CAMPAIGN MANAGEMENT $>$ ADVERTISING $>$ ADVERTISING EFFECTIVENESS ADVERTISING EFFECTIVENESS, MEASUREMENT OF ADVERTISING AS PERSUASION $>$ BRANDS COGNITIVE SCIENCE

INFORMATION PROCESSING MARKETING MEDIA PLANNING $>$ PERSUASION SEGMENTATION OF THE ADVERTISING AUDIENCE V VALIDITY

\section{REFERENCES AND SUGGESTED READINGS}

Armstrong, J. S. (2010). Persuasive advertising: Evidence-based principles. Basingstoke: Palgrave Macmillan.

Franzen, G. (1999). Brands and advertising: How advertising effectiveness influences brand equity. Henleyon-Thames: Admap.

Rossiter, J. R. \& Percy, L. (1998). Advertising communications and promotions management. Boston: Irwin and McGraw-Hill.

Stewart, D. W. \& Furse, D. H. (1986). Effective television advertising: A study of 1000 commercials. Lexington, MA: Lexington. 
Van den Putte, B. (2002). An integrative framework for effective communication. In G. Bartels \& W. Nelissen (eds.), Marketing for sustainability: Towards transactional policy-making. Amsterdam: IOS Press, pp. 83-95.

\section{Advocacy Journalism}

\section{ROBERT JENSEN}

University of Texas at Austin

The term 'advocacy journalism' describes the use of journalism techniques to promote a specific political or social cause. Other terms used for practice outside the mainstream include 'alternative,' 'gonzo, or 'new journalism' $\rightarrow$ Alternative Journalism). The term is potentially meaningful only in opposition to a category of journalism that does not engage in advocacy, so-called objective journalism ( $\rightarrow$ Objectivity in Reporting).

This advocacy/objectivity dichotomy springs from political theory that asserts a special role for journalists in complex democratic societies. Journalists' claims to credibility are based in an assertion of neutrality. They argue for public trust by basing their report of facts, analysis, and opinion on rigorous information gathering. Professional self-monitoring produces what journalists consider an unbiased account of reality, rather than a selective account reflecting a guiding political agenda.

At one level, the term 'advocacy' might be useful in distinguishing, for example, journalistic efforts clearly serving a partisan agenda (such as a political party publication) from those officially serving nonpartisan ends (such as a commercial newspaper). But the distinction is not really between forms of journalism as much as between persuasion and journalism. Although so-called objective journalism assumes that, as a rule, disinterested observers tend to produce more reliable reports, a publication advocating a cause might have more accurate information and compelling analysis than a nonpartisan one. The intentions of those writing and editing the publication are the key distinguishing factor.

All reporters use a framework of analysis to understand the world and report on it. But reporting that contains open references to underlying political assumptions and conclusions seems to engage in advocacy, while the more conventional approach appears neutral. Both are independent in the sense of not being directed by a party or movement, but neither approach is in fact neutral. One explicitly endorses a political perspective critical of the powerful, while the other implicitly reinforces the political perspective of the elite ( $\rightarrow$ News Ideologies).

\section{See also: ALTERNATIVE JOURNALISM \\ JOURNALISTS' ROLE PERCEPTION $>$ NEWS IDEOLOGIES $>$ OBJECTIVITY IN REPORTING}

\section{REFERENCES AND SUGGESTED READINGS}

Applegate, E. (2009). Advocacy journalists: A biographical dictionary of writers and editors Lanham, MD: Scarecrow Press.

Collings, A. (2001). Words of fire: Independent journalists who challenge dictators, druglords, and other enemies of a free press. New York: New York University Press.

Kessler, L. (1984). The dissident press: Alternative journalism in American history. Newbury Park, CA: Sage.

Mindich, D. T. Z. (1998). Just the facts: How "objectivity" came to define American journalism. New York: New York University Press.

\section{Affective Disposition Theories}

\section{ARTHUR A. RANEY \\ Florida State University}

Affective disposition theory (ADT) explains the process by which we enjoy different entertainment narratives. The theory conceptualizes media enjoyment - primarily thought of in hedonic terms - as the product of a viewer's emotional affiliations (i.e., affective dispositions) with characters and the outcomes experienced by those characters in the narrative $(\rightarrow$ Parasocial Interactions and Relationships).

ADT contends that we form dispositions toward media characters in much the same way we do with people in the real world. First, we tend to like those whom we perceive to be similar to ourselves, with those perceptions being filtered through a moral lens. Thus, moral 
considerations govern the valence of the dispositions we form, with characters whose actions and motivations are judged to be morally correct liked more. Second, the intensity of those dispositions vary on a continuum from extremely positive through indifference to extremely negative, and may fluctuate as the narrative unfolds. Third, affective dispositions trigger empathybased reactions toward things experienced by characters. As a result, with beloved protagonists, we hope for their success and fear for their failure; with hated villains, we desire the opposite. Finally, if the outcomes wished for by viewers are depicted in the narrative, then enjoyment increases in proportion to the strength of the affective dispositions held. If those hoped-for outcomes are not portrayed, then enjoyment suffers in proportion to the strength of the dispositions.

Despite subtle operational variations, the basic $\mathrm{ADT}$ formula has been demonstrated as stable across various genres, including humor, drama, frightening fare, $\rightarrow$ reality TV, sports, and digital games ( $\rightarrow$ Digital Imagery). Current ADT research further explores these cross-genre differences, as well as issues related to viewer and character morality, discrete emotional reactions toward characters, how expectations impact enjoyment, and non-hedonic/meaningful media experiences.

\section{See also: DIGITAL IMAGERY FICTION \\ MOOD MANAGEMENT $>$ PARASOCIAL \\ INTERACTIONS AND RELATIONSHIPS DEALITY TV \\ SELECTIVE EXPOSURE $>$ USES AND \\ GRATIFICATIONS}

\section{REFERENCES AND SUGGESTED READINGS}

Raney, A. A. (2004). Expanding disposition theory: Reconsidering character liking, moral evaluations, and enjoyment. Communication Theory, 14(4), 348-369.

Zillmann, D. (2000). Basal morality in drama appreciation. In I. Bondebjerg (ed.), Moving images, culture, and the mind. Luton: University of Luton Press, pp. 53-63.

Zillmann, D. \& Cantor, J. (1976). A disposition theory of humor and mirth. In T. Chapman \& H. Foot (eds.), Humor and laughter: Theory, research, and application. London: Wiley, pp. 93-115.

\section{Affects and Media Exposure}

ELLY A. KONIJN

Vrije Universiteit Amsterdam

Affect covers various concepts, such as moods, feelings, and emotions and indicates either a positive or negative feeling state. Mood relates to an enduring affective state, no felt urgency, and not clearly elicited by an external event. Moods may also have a biochemical source, such as experimentally induced epinephrine effects. Emotion is clearly defined by a specific event, with a beginning and ending, has an object and relates to meaningful events. Emotions comprise the felt need to (not) act to serve one's goals or concerns. Experiencing (or felt) emotions should be differentiated from the expression of emotions (depicted).

Mood management theory states that people select particular media programming in order to avoid negative and restore pleasant feeling states ( $\rightarrow$ Mood Management). Through empathy with the sufferings of others, we feel empathic distress and fear for the fate of the sympathetic protagonist, whereas we hope for the devastation of his/ her rivals ( $\rightarrow$ Affective Disposition Theories). Numerous related concepts have evolved such as $\rightarrow$ parasocial interactions and relationships or $\rightarrow$ presence. Scholars proposed using an umbrella concept (e.g., emotional involvement; appreciation) to be defined in terms of a tradeoff of parallel positive (e.g., empathy) and negative (e.g., detachment) affects (Konijn \& Hoorn 2005).

Furthermore, uses and gratifications theory states that we seek media exposure for affective, informative, social, or dispersion-seeking motivations ( $\rightarrow$ Escapism; Uses and Gratifications). Social Comparison Theory adds that looking at others' sufferings may make us feel better $(\rightarrow$ Social Comparison Theory). Aggressiveness from violent media exposure has largely been studied from a $\rightarrow$ social cognitive theory perspective ( $\rightarrow$ Violence as Media Content, Effects of). Emotion psychology further explains why we seek affective gratifications by media exposure just for the sake of being moved and the social sharing of emotions following basic human needs (Konijn 2012).

In the context of $\rightarrow$ persuasion, ads, and commercials, the study of affect, mood, and emotions 
has evolved as a field on its own, because (even negative) "emotions sell” (Williams \& Aaker 2002; $\rightarrow$ Advertising Effectiveness). Mostly studied are fear appeals $(\rightarrow$ Fear Induction through Media Content), humor, and attaching sexual affect to commercial content in creating a positive association with the product. The results of such affectladen advertisements are mixed because consumers may remember the affect-arousing image (e.g., the joke) but not the message, the affect-laden images may not match with the advertised product, or be considered irrelevant by the consumer. In addition, social factors like watching with friends and relatives may further increase the affective response and the program's effectiveness.

Through the world-wide-web, much traditional media fare is readily available alongside interactive digital offerings, such as online gaming and $\rightarrow$ social media. As in real life, social and virtual lives are filled with affect and emotions. For example, boys play violent games to vent their anger, while others are engaged in cyberbullying, reviving the moral panic debate. Affective computing (Picard 1997) is an emerging research field focused on adding emotion to technology to make the interaction more human-like. Importantly, increased interaction with 'virtual others', such as virtual tutors, synthetic health coaches, and care robots is foreseen due to aging and limited resources.

Affect, moods, and emotions influence how the information derived from media exposure is processed ( $\rightarrow$ Information Processing). Emotional processing limits the capacity to cognitively process and store the information. Systematic (experimental) studies are scarce, especially on the role of emotions in acquiring real-world knowledge from fictional content. Research shows that emotionalized viewers are more inclined to take fiction for real than are non-emotional viewers. Based on neurobiological and developmental neuroscience, these scholars argued that because emotions are our 'life-vests', they tell us what information to take seriously - mediated or not (Konijn 2012). Future research is warranted in detailing how affective processing of media fare impacts our knowledge structures, especially given our current 'mediated society' and the hybrid 'reality status' of many media messages, where affect and emotions may take the lead.

See also: $\gg$ ADVERTISING EFFECTIVENESS

$\checkmark$ AFFECTIVE DISPOSITION THEORIES \ APPRAISAL
THEORY ENTERTAINMENT CONTENT AND REALITY PERCEPTION $\$ ESCAPISM $>$ FEAR INDUCTION THROUGH MEDIA CONTENT INFORMATION PROCESSING IINVOLVEMENT WITH MEDIA CONTENT INFORMATION PROCESSING D MOOD MANAGEMENT PARASOCIAL INTERACTIONS AND RELATIONSHIPS $>$ PERSUASION $>$ PRESENCE

$>$ SELECTIVE EXPOSURE $>$ SOCIAL COGNITIVE THEORY \SOCIAL COMPARISON THEORY \SOCIAL MEDIA USES AND GRATIFICATIONS VIOLENCE AS MEDIA CONTENT, EFFECTS OF

\section{REFERENCES AND SUGGESTED READINGS}

Döveling, K., Von Scheve, C., \& Konijn, E. A. (eds.) (2010). The Routledge handbook of emotions and mass media. London: Routledge.

Frijda, N. H. (1986). The emotions. Cambridge: Cambridge University Press.

Konijn, E. A. (2012). The role of emotion in media use and effects. In: Dill, K. (ed.). The Oxford handbook of media psychology. Oxford: Oxford University Press, pp. 186-211.

Konijn, E. A. \& Hoorn, J. F. (2005). Some like it bad. Media Psychology, 7(2), 107-144.

Picard, R. W. (1997). Affective computing. Cambridge, MA: MIT Press.

Williams, P. \& Aaker, J. L. (2002). Can mixed emotions peacefully coexist? Journal of Consumer Research, 28, 636-649.

\section{Africa: Media Systems}

\section{WINSTON MANO \\ University of Westminster}

This entry concentrates on media systems in countries of Sub-Saharan Africa. The Sub-Saharan media system was born in the colonial era. The use of European languages, state-biased ownership systems, and limited media freedom are among colonial media attributes that continue in Sub-Saharan Africa, a 48-country region that is huge and diverse.

The spread and access to the mass media in Sub-Saharan Africa has been a highly uneven process. Among old media, radio has achieved the best penetration owing to its affordability and adaptability. Even the largely urban and elitist medium of television has shown remarkable growth in Africa. The figures for print media titles published in Sub-Saharan Africa also show a marked increase in titles and the total average circulation of 
dailies (World Association of Newspapers 2009). Today's rapid growth of the African media belies the fact that these mass media are recent and that they were mainly introduced during the colonial era.

\section{Print and Radio}

One of the most obvious features of Sub-Saharan African media is the way print media were introduced in different parts of the region. The press in English-speaking West Africa was the earliest in Sub-Saharan Africa. Missionaries also helped introduce newspapers in the region. By contrast to patterns in West Africa, in Anglophone Southern and Central Africa, the press was largely introduced by European settlers. The most notable newspapers at this time included the "Cape Argus," founded in 1857. The beginnings of the press in East Africa were not different from other parts of Africa. It was largely created for its settler population.

The French colonial administration in Africa actively discouraged the development of the press in the colonies. A heavy tax was placed on imported newsprint and printing machinery and in keeping with their policy of assimilation of Africans into French culture they preferred to freely circulate newspapers produced in the metropolis to their African colonies.

The introduction and organization of radio closely followed colonial political and administrative systems. The British deliberately promoted the use of local languages in an attempt to build an African audience. The French, unlike the British, who wanted to provide something of a public service to their colonies, pursued an entirely different policy and initially delayed the start of broadcasting in their colonial territories. French colonial policy of direct rule was mirrored in broadcasting, as all programming was initially French in orientation and in delivery. The Belgians left broadcasting to private individuals or religious groups. In both the French and the British colonies, radio was from the outset an arm for colonial policies ( $\rightarrow$ Radio for Development; Radio: Social History).

\section{The Television Age}

The television age came to Sub-Saharan Africa in the late 1950s, which was the period when colonial rule ended for many countries in the region. Elite and urban in character, television depended on foreign programming and was initially used mainly for entertainment purposes. Several Sub-Saharan African countries resisted television for many years. South Africa resisted television until 1976, because of what was seen by the apartheid government as its 'morally corruptive' influence and fears that it could provide information that would strengthen anti-apartheid forces ( $\rightarrow$ Cultural Imperialism Theories). However, for most countries in the region, the television age coincided with national independence, but the medium sadly remains a symbol of national status that hardly goes beyond the major African cities ( $\rightarrow$ Television for Development).

\section{Independence and Democratization}

Although colonial media were used to suppress and misinform Sub-Saharan Africans, alternative media also helped them achieve political independence in the 1960s. Post-independence media systems were close to one-party systems. In the processes of nation building, the ownership and control of broadcasting was more centralized than that of print media. On the whole, the legacy of western notions of media culture and practice is yet to be adequately reformed in order to address the expectations of the majority of Africans, especially those living in rural Africa.

In the 1990s, the changing African media became central to the new struggle for greater political and economic independence. By 2005, most countries had opened up their broadcasting sectors after many years of state monopoly of the sector. The 1990s ushered in a boom in private, local, community, and commercial radio stations across the regions ( $\rightarrow$ Community Media). In general, a wave of democracy in the 1990s brought with it multipartyism and a degree of media pluralism in many Sub-Saharan African countries ( $\rightarrow$ Communication Law and Policy: Africa).

\section{The Twenty-First-Century African Media System}

From 2000 to 2006 the number of Internet users in Africa grew by 625.8 percent. Such rapid growth was mainly driven by a rapid increase in mobile phone (cell phone) subscribers in the 
region, making Africa the first place where mobile subscribers outnumber fixed-line subscribers.

However, the overall picture in Sub-Saharan African countries seems to suggest that a very small group of privileged Africans have benefited. Regulatory and technological issues dominate the twenty-first-century African media system. State monopolies have been undermined by a wave of deregulation, commercialization, and privatization of broadcasting and telecommunications ( $\rightarrow$ Commercialization: Impact on Media Content).

A small but significant number of Africans is now able to receive popular radio and television content via terrestrial, satellite, cable, and Internet ( $\rightarrow$ Satellite Television). Most countries are taking advantage of the rapid development of new communications technologies and digitization. Sub-Saharan Africa has also seen a dramatic growth in the indigenous entertainment production industry such as the video film sector in Nigeria, now dubbed 'Nollywood.' Internet radio stations, online newspapers, and digital music libraries are set to continue revolutionizing the Sub-Saharan African media scene. To sum up, Sub-Saharan Africa's emerging media system is diverse and fast growing but to a large extent is heavily influenced by its colonial legacy.

See also: CENSORSHIP COMMERCIALIZATION: IMPACT ON MEDIA CONTENT COMMUNICATION LAW AND POLICY: AFRICA $>$ COMMUNITY MEDIA

CULTURAL IMPERIALISM THEORIES $>$ DIGITAL MEDIA, HISTORY OF EDUCATIONAL

COMMUNICATION $>$ POLITICAL COMMUNICATION

RADIO FOR DEVELOPMENT RADIO: SOCIAL HISTORY $>$ SATELLITE TELEVISION

TELEVISION FOR DEVELOPMENT

\section{REFERENCES AND SUGGESTED READINGS}

Bourgault, L. M. (1995). Mass media in Sub-Saharan Africa. Bloomington, IN: Indiana University Press.

Fardon, R. \& Furniss, G. (eds.) (2000). African broadcast cultures: Radio in transition. Oxford: James Currey.

Honeyman, R. (2003). African regulation of satellite broadcasting in the era of convergent ICTS. In Broadcasting policy and practice in Africa. London: Article 19, pp. 71-113.

Internet World Stats (2014). Internet usage statistics for Africa. At http://www.internetworldstats.com/stats1. htm, accessed July 16, 2014.
Mudhai, O. F., Tettey, W., \& Banda, F. (eds.) (2009). African media and the digital public sphere. Basingstoke: Palgrave Macmillan.

Mytton, G. (1983). Mass communication in Africa. London: Edward Arnold.

Mytton, G. (2000). Sub-Saharan surveys: From saucepan to dish-radio and TV in Africa. In R. Fardon \& G. Furniss (eds.), African broadcast cultures: Radio in transition. Oxford: James Currey.

Nyamnjoh, F. (2005). Africa's media: Democracy and the politics of belonging. London: Zed Books.

World Association of Newspapers (2009). Shaping the future of the news. Paris. World Association of Newspapers and ZenithOptimedia.

World Bank (2006). World Bank indicators 2006. Washington, DC: World Bank.

\section{Age Identity and Communication}

\section{JAKE HARWOOD}

University of Arizona

Communication plays a substantial role in influencing understandings and self-presentations with regard to age. While increasing chronological age is at the heart of life-span development issues, our age group identifications and the age groups into which we are categorized are not deterministically organized by chronological age; they are malleable, and divisions between age groups are negotiated and open to socio-communicative construction ( $\rightarrow$ Discursive Psychology). Negative age stereotypes and prejudicial (ageist) attitudes are common (despite the fact that most of us will get old), which provides unique opportunities for identity scholars. A detailed overview of many of these processes is provided in Harwood (2007).

One approach to age identification and communication has been to examine intergenerational processes driven by age categorizations $(\rightarrow$ Intergenerational Communication). Grounded in social identity theory and $\rightarrow$ communication accommodation theory, this work examines how age stereotypes lead to patronizing or baby-talk speech from young to old; this speech appears grounded in stereotypes of deafness or mental decline ( $\rightarrow$ Intergroup Accommodative Processes). This talk is often dissatisfying for older adults, and can yield negative outcomes, particularly as the 
older recipients of such speech are assumed to be incompetent by those overhearing it. Ryan et al. (1986) present core theory on this topic (the 'communication predicament of aging' model). Kemper and Harden (1999) describe disentangling the elements of this speech that are functional vs. counterproductive. Intergroup age stereotyping processes are closely related to age identities $(\rightarrow$ Prejudiced and Discriminatory Communication). Other intergenerational processes are tied to life-span identifications: storytelling ( $\rightarrow$ Storytelling and Narration); attribution; reproaching; disclosing painful experiences, and intergenerational conflict. Much of this research is culturally limited and more work should examine cultural variability (e.g., laodao is a specifically Chinese pattern of repetitive complaining from old to young).

Age identities are raised, manipulated, avoided, and negotiated in naturalistic language use or discourse (Coupland \& Coupland $1990 \rightarrow$ Identities and Discourse). This includes work examining the disclosure of chronological age (DCA) in older adulthood (i.e., when and why older adults tell others exactly how old they are). Age categories are invoked in other ways too. An age-related role can be mentioned (widow, student, retiree), or descriptions of changes over time can be made (comparing past to present). Raising age in discourse serves particular discursive and identity purposes.

Age identities are shaped by media. Older people are underrepresented and devalued on television (Robinson et al. 2004), as are very young people (children and adolescents). Quantitative analyses also show that older people are often portrayed negatively ( $\rightarrow$ Social Stereotyping and Communication). Some qualitative work examines age representations in websites, skin care and tanning discourses, Internet chat rooms, and on specific television shows such as The Golden Girls. Further work should examine how aging is used in cosmetics advertising (e.g., anti-wrinkle creams), $\rightarrow$ news stories, extreme counter-stereotypical activities (sky diving), and $\rightarrow$ advertising.

Aging is often treated as synonymous with ill health and decline (Hummert \& Nussbaum 2001; $\rightarrow$ Health Communication). Anti-ageist medical philosophies are sometimes invoked by physicians in dealing with older patients. These philosophies are well intentioned and may help some patients, however others may find comfort in attributing health problems to age.
See also: $>$ ADVERTISING $>$ AGING AND

MESSAGE PRODUCTION AND PROCESSING

COMMUNICATION ACCOMMODATION THEORY

DISCURSIVE PSYCHOLOGY $>$ HEALTH

COMMUNICATION IDENTITIES AND DISCOURSE

$\checkmark$ INTERCULTURAL AND INTERGROUP

COMMUNICATION INTERGENERATIONAL

COMMUNICATION INTERGROUP ACCOMMODATIVE

PROCESSES \ NEWS STORY PREJUDICED AND

DISCRIMINATORY COMMUNICATION D SOCIAL

STEREOTYPING AND COMMUNICATION

STORYTELLING AND NARRATION

\section{REFERENCES AND SUGGESTED READINGS}

Coupland, N. \& Coupland, J. (1990). Language and later life: The diachrony and decrement predicament. In H. Giles \& W.P. Robinson (eds.), The handbook of language and social psychology. Chichester: John Wiley, pp. 451-468.

Harwood, J. (2007). Understanding communication and aging: Developing knowledge and awareness. Thousand Oaks, CA: Sage.

Hummert, M.L. \& Nussbaum, J.F. (2001).Communication, aging, and health. Mahwah, NJ: Lawrence Erlbaum.

Kemper, S. \& Harden, T. (1999). Experimentally disentangling what's beneficial about elderspeak from what's not. Psychology and Aging, 14, 656-670.

Robinson, J. D., Skill, T., \& Turner, J. W. (2004). Media usage patterns and portrayals of seniors. In J. F. Nussbaum \& J. Coupland (eds.), Handbook of communication and aging research, 2nd edn. Mahwah, NJ: Erlbaum, pp. 423-450.

Ryan, E. B., Giles, H., Bartolucci, G., \& Henwood, K. (1986). Psycholinguistic and social psychological components of communication by and with the elderly. Language and Communication, 6, 1-24.

\section{Agenda Building}

MATTHEW C. NISBET

American University

Agenda building refers to the process by which news organizations and journalists select certain events, issues, or sources to cover over others. The agendabuilding literature is characterized by a diversity of theoretical and methodological approaches. However, a common thread is that news coverage is not a reflection of reality, but rather determined by a hierarchy of social influences (Shoemaker \& Reese 1996; $\rightarrow$ Reality and Media Reality). 
Research, for example, has explored the impact of ownership structure on the issues and plurality of perspectives considered newsworthy. Additionally, several scholars have examined how changes in technology and market forces have displaced coverage of policy-oriented hard news issues with coverage of soft news topics ( $\rightarrow$ Media Economics). Other research has focused on intermedia agenda setting, or the tendency for different types of news outlets to mirror closely the set of issues covered by just a few national news organizations.

Yet, most of the research on agenda building has focused on workplace and professionallevel influences that shape news attention. This research investigates the unofficial set of ground rules that govern the interactions between journalists and their sources, privileging attention to certain issues, views, and societal actors over others.

Faced with financial and time pressures, journalists routinize their daily work by relying on $\rightarrow$ news values such as prominence, conflict, drama, proximity, timeliness, and objectivity ( $\rightarrow$ News Factors). They also rely heavily on storytelling themes and narrative to package complex events and issues and to make them appealing to specific audiences. In reporting the news, they often follow a common set of organizational rules, professionally derived standards of ethics and quality, shared judgments of authority and expertise and societal expectations relative to commonly held beliefs such as patriotism or religion ( $\rightarrow$ Ethics in Journalism). More recent work has examined how the cognitive and emotional needs of journalists can help explain common agenda-building phenomena, ranging from pack journalism to political bias (Donsbach 2004; $\rightarrow$ Bias in the News).

\section{See also: B BIAs IN THE NEWS D ETHICS IN JOURNALISM MEDIA ECONOMICS $>$ NEWS FACTORS $>$ NEWS VALUES $>$ QUALITY OF THE NEWS $>$ REALITY AND MEDIA REALITY}

\section{REFERENCES AND SUGGESTED READINGS}

Donsbach, W. (2004). Psychology of news decisions: Factors behind journalists' professional behavior. Journalism, 5, 131-157.
Shoemaker, P. J. \& Reese, S. D. (1996). Mediating the message: Theories of influence on mass media content. White Plains, NY: Longman.

\section{Agenda-Setting Effects}

\section{DAVID H. WEAVER}

Indiana University

One of the most frequently cited approaches to studying media effects is known as the agendasetting effect (or function) of mass media. First tested empirically in the 1968 US presidential election by North Carolina journalism professors Maxwell McCombs and Donald Shaw (McCombs \& Shaw 1972), this approach originally focused on the ability of the mass media to tell the public what to think about rather than what to think. This was a sharp break from previous media effects studies that had focused on what people thought (their opinions and attitudes) and on behaviors such as voting ( $\rightarrow$ Media Effects, History of).

Since this initial study of media agenda setting, there have been hundreds of studies carried out by scholars in many countries (McCombs 2004) on several aspects of agenda setting. Most of these have focused on the relationship between news media ranking of issues (by amount and prominence of coverage) and public rankings of the perceived importance of these issues in various surveys, a type of research that Dearing and Rogers (1996) have called 'public' agenda setting, to distinguish it from studies that are concerned mainly with influences on the media agenda ('media' agenda setting) or on public policy agendas ('policy' agenda setting).

The evidence from scores of public agendasetting studies is mixed, but on the whole it tends to support a positive correlation - and often a causal relationship - between media agendas and public agendas at the aggregate (or group) level, especially for relatively unobtrusive issues that do not directly impact the lives of the majority of the public, such as foreign policy and government scandal. At the individual level, the evidence is not as strong (Shehata \& Strömbäck 2013). In the majority of studies to date, the unit of analysis on each agenda is an object, a public issue. But objects have attributes, or characteristics. Due to the limited capacity of the news agenda, however, journalists can only present a few aspects of any object in the news. Similarly, when people talk 
about and think about these objects - public issues, political candidates, etc. - the attributes ascribed to these objects also vary considerably in their salience. These agendas of attributes have been called 'the second level' of agenda setting to distinguish them from the first level, which has traditionally focused on issues (objects). The perspectives and frames that journalists employ draw attention to certain attributes of the objects of news coverage, as well as to the objects themselves ( $\rightarrow$ Framing Effects; Framing of the News).

Takeshita (2006) has identified three critical problems with agenda-setting research: process, identity, and environment. The 'process problem' focuses on the degree to which agenda setting is automatic and unthinking; the 'identity problem' is concerned with whether second-level or attribute agenda setting will become indistinguishable from framing or traditional persuasion research; and the 'environment problem' stems from the growth in the number of news outlets, and whether that will reduce and fragment the agenda-setting effect of media at the societal level.

Takeshita suggests that future research on agenda setting should focus on the factors that distinguish genuine or deliberative agenda setting from 'pseudo agenda setting' that is automatic and unthinking. He also suggests focusing on how the salience of certain attributes of a given object (be it an issue or a candidate) leads to the development of attitudes toward that object. In addition, it seems clear that more research is needed to clarify the similarities and differences between second-level agenda setting and framing, to specify the conditions under which media agendas are likely to influence not only public but also policymakers' agendas (Tan \& Weaver 2010), and to study the influences on the media agenda.

\section{See also: CONTENT ANALYsis, QUANTITATIVE \\ CORRELATION ANALYSIS FRAMING EFFECTS \\ FRAMING OF THE NEWS I INFORMATION \\ PROCESSING MEDIA EFFECTS, HISTORY OF \\ MEMORY PRIMING THEORY PUBLIC OPINION $>$ SURVEY}

\section{REFERENCES AND SUGGESTED READINGS}

Dearing, J. W. \& Rogers, E. M. (1996). Agenda-setting. Thousand Oaks, CA: Sage.
McCombs, M. (2004). Setting the agenda: The mass media and public opinion. Cambridge: Polity. (2nd edn in press.)

McCombs, M. E., \& Shaw, D. L. (1972). The agendasetting function of mass media. Public Opinion Quarterly, 36, 176-187.

Shehata, A. \& Strömbäck, J. (2013). Not (yet) a new era of minimal effects: A study of agenda setting at the aggregate and individual levels. Harvard International Journal of Press / Politics, 18(2), 234-255.

Takeshita, T. (2006). Current critical problems in agenda-setting research. International Journal of Public Opinion Research, 18(3), 275-296.

Tan, Y. \& Weaver, D. H. (2010). Media bias, public opinion, and policy liberalism from 1956 to 2004: A second-level agenda-setting study. Mass Communication and Society, 13(4), 412-434.

\section{Aging and Message Production and Processing}

\section{SUSAN KEMPER}

University of Kansas

Aging affects many aspects of message production and processing. The nature of conversation changes: older adults mix talk about the past with talk about the present, sharing by 'painful self-disclosures' of bereavement, ill health, and personal problems ( $\rightarrow$ Intergenerational Communication). Younger adults adopt elderspeak, a speech style characterized by exaggerated pitch and intonation, simplified grammar, limited vocabulary, a slow rate, 'we' pronouns, and diminutives like 'honey.' Elderspeak reinforces negative stereotypes of older adults as "child like", and expresses a sense of disrespect, limiting conversational interactions and contributing to older adults' social isolation and cognitive decline ( $\rightarrow$ Language and Social Interaction).

Older adults' conversational skills may be affected by the breakdown of inhibition, whereby irrelevant thoughts, personal preoccupations, and idiosyncratic associations intrude. Older adults' speech can be verbose and off-target. Older adults often experience the inability to recall a well-known word, name, or title when connections between the idea to words' phonology are broken. Such broken links become more numerous with aging, disrupting conversations, shifting the conversation from the topic under 
discussion to a focus on the older adults' memory problems ( $\rightarrow$ Speech Fluency and Speech Errors). Dementia accelerates and exaggerates age-related changes, especially the use of elderspeak, offtarget verbosity, and word-finding problems, which contribute to caregiver burden, poor care, and poor quality of life for those with dementia.

A growing area of investigation concerns multitasking. The demands of even walking and talking at the same time may over-task older adults, detracting from their ability to process or produce messages and contributing to increased risk for falls or other accidents. New technologies offer the possibility of remediating for many agerelated problems but also create new problems: How to optimize synthesized speech for older adults? Will older adults accept and trust health and medical recommendations administered by a 'nurse-bot'? How can websites be designed to facilitate older adults' search and retrieval of information?

\section{See also: INTERGENERATIONAL COMMUNICATION $>$ LANGUAGE AND SOCIAL INTERACTION $>$ MEANING $>$ MESSAGE PRODUCTION $>$ SOCIAL STEREOTYPING AND COMMUNICATION $>$ SPEECH FLUENCY AND SPEECH ERRORS}

\section{SUGGESTED READINGS}

Kemper, S. (2011). The effects of aging on language and communication. In R. Peach \& L. Shapiro (eds.), Cognition and acquired language disorders: A processoriented approach. San Diego: Elsevier.

\section{Alternative Journalism}

\section{JON BEKKEN}

Albright College

Alternative journalism is a fluid concept, often attributed to media practices unified only by their differing from mainstream $\rightarrow$ journalism. Recent scholarship focuses on practices that challenge the communicator/audience divide, including the range of voices presented, the privileging of marginalized news sources over traditional elites, a conscious identification with the audience being served, and a conception of journalism that promotes social action (Atton 2002; Downing 2001; $\rightarrow$ Citizen Journalism; Community Media; Development Journalism).

Dissidents have long contested the terrain of mass communications, from the underground printing presses used in eighteenth-century France to the anonymizers and remote hosting sites bloggers use to evade censors ( $\rightarrow$ Censorship). Throughout the nineteenth century, newspapers were central to Chartists' and socialists' efforts to build an oppositional working-class culture and campaign for their demands. Social media were widely credited with facilitating the Arab Spring that challenged regimes across the Middle East $(\rightarrow$ Social Media).

Alternative journalism embraces advocacy, and does not so much serve its audience as constitute a process of cultural empowerment, creating and maintaining an alternative $\rightarrow$ public sphere that enables diverse publics to speak in their own voice (Rodríguez 2001; $\rightarrow$ Advocacy Journalism; Objectivity in Reporting; Journalists' Role Perception). Alternative journalism thus challenges the $\rightarrow$ professionalization of journalism. The labor press combined staff reports with articles written by readers, often describing their own working conditions and local struggles. These newspapers were often published by cooperatives that raised the necessary funds, elected editors, and convened regular meetings at which editors reported to their readers.

Today alternative journalists work in every medium, from clandestinely circulated news bulletins to the Free Speech Television Network. Although the so-called marketplace of ideas remains relentlessly inhospitable to alternative journalism, media activists continue to seize on new technologies and underserved audiences in their quest to forge a new kind of media practice.

\footnotetext{
See also: ADVOCACY JOURNALISM

CENSORSHIP $>$ CITIZEN JOURNALISM

COMMUNITY MEDIA DEVELOPMENT

JOURNALISM $>$ ETHNIC JOURNALISM $>$ FEMINIST

MEDIA > JOURNALISM D JOURNALISM, HISTORY

OF JOURNALISTS' ROLE PERCEPTION

MINORITY JOURNALISM OBJECTIVITY IN REPORTING $>$ PARTICIPATORY COMMUNICATION

PROFESSIONALIZATION OF JOURNALISM

PUBLIC SPHERE $>$ SOCIAL MEDIA
} 


\section{REFERENCES AND SUGGESTED READINGS}

Atton, C. (2002). Alternative media. London: Sage.

Downing, J. (2001). Radical media: Rebellious communication and social movements. Thousand Oaks, CA: Sage.

Rodríguez, C. (2001). Fissures in the mediascape: An international study of citizens' media. Cresskill, NJ: Hampton.

\section{Anime}

\section{ANNE COOPER-CHEN}

Ohio University

The term anime is abbreviated from the Japanese word animēshon, which in turn is a direct transliteration of the English word animation. Comprising mainly Japanese TV series, anime features unique aesthetics, and range from action and drama to fantasy, horror, and comedy. The setting may be contemporary, futuristic, historic, or fantastical. Anime and related products manga, toys, and $\rightarrow$ video games - challenge the worldwide dominance of US popular media. Starting as a major influence in about 1995 and abetted by the Internet, Japanese pop youth culture has spread not just to the US, but also to Europe (notably France), East Asia, and Latin America. In addition to half-hour TV episodes, the field of anime includes films, such as Hayao Mizaki's Spirited Away (winner of the US 2003 Animated Feature Oscar).

One can think of cartoons in Japan as a pyramid ( $\rightarrow$ Japan: Media System). At the bottom reside manga, thick periodicals printed on cheap newsprint that contain multiple storylines. At the next level are cartoon books of popular manga storylines. Moving up, one finds some of the books taking on life as Japanese-language TV anime or films. Of those, a few find their way overseas, either dubbed or subtitled. For example, a 1980 manga found new life as the 2011 movie From Up on Poppy Hill, directed by Hayao Miyazaki's son Goro (it grossed \$61 million worldwide).

A noticeable anime (and manga) hallmark is characters' unnaturally large eyes, a legacy of the revered artist Osamu Tezuka (1928-1989) not necessarily to achieve a foreign look, but because eyes could empathetically reflect emotions
( $\rightarrow$ Disney). Japan's first TV animation was broadcast in 1963, Tezuka's 30-minute series Tetsuwan Atom; it met with phenomenal success (a rating of 40.7 percent). As Astro Boy, the series was successfully exported. In the later 1960s, the dubbed Speed Racer became a children's TV series overseas. Japanese-ness was not evident in either anime.

The year 1995 marked a turning point for exports, when identifiably Japanese anime Dragon Ball and Sailor Moon appeared. Then in 1998 two blockbusters debuted: Pokemon for children and Dragon ball Z, which as Z became Cartoon Network's top-rated show. In 2013, 11 dubbed TV anime were running on that network. Overseas anime's status today ranks between a niche phenomenon and - especially in larger cities - a major cultural force.

\section{See also: CINEMA DISNEY $>$ JAPAN: MEDIA SYSTEM $>$ VIDEO GAMES}

\section{REFERENCES AND SUGGESTED READINGS}

Cooper-Chen, A. (2010). Cartoon cultures: The globalization of Japanese popular media. New York: Peter Lang.

Napier, S. J. (2007). From impressionism to anime. New York: Palgrave Macmillan.

Richmond, S. (2009). The rough guide to anime. New York: Rough Guides.

\section{Applied Communication Research}

\section{DAVID R. SEIBOLD}

University of California, Santa Barbara

Applied communication research refers to a type of communication scholarship as well as to a subfield of communication. In the first sense, applied communication scholarship emphasizes the creation of knowledge about communication in specific contexts, applicable to social issues, and often for the solution of societal problems. In the second, applied communication research references a sub-area of the discipline. Most evident in the United States, these sub-field structures serve as an umbrella for many professional practices and research foci. 
While Eadie's (1982) “case for applied communication research" justified the area, disputes surrounding its legitimacy, the problematic dichotomy between 'basic' and 'applied' research, and the relationship between theory and practice have arisen and abated (Seibold 2000). Applied communication researchers acknowledge the recursivity of theory and practice, but do not agree on the extent to which they are equal aspects of applied communication research nor the extent to which they can/must be mutually informing (Seibold 2005). Applied communication researchers also differ on where to enter the circle for analytic or ameliorative purposes and how to insure both are retained in that process, including how to preserve scholarship in pursuit of service.

There are discernible trends in applied communication research. First, the range of research methods has broadened to include all of those in the communication discipline. Second, the evolving nature of the discipline has been mirrored in the evolution of applied communication research. Articles in the Journal of Applied Communication Research (JACR) reflect the scholarly foci of all divisions in the National Communication Association, the journal's sponsoring organization. Third, applied communication scholarship addresses a wider range of problems. Fourth, the number of scholars doing applied communication research has increased, as has their depth of engagement with problematic societal issues.

Finally, there has been an effort to delineate alternative forms of "engaged communication scholarship" (Dempsey \& Barge, 2014). For example, Putnam (2009) distinguished applied communication research from other "faces" of engaged scholarship such as collaborative learning, activism and social justice, and practical theory. Applied communication research is problem-centered, and seeks to generate usable knowledge or to make extant theory and research findings applicable to real-world issues. Interventions usually follow the research process rather than occurring simultaneously. Applied communication research vocabularies include problem-orientation, relevance, and translation.

Cissna, Eadie, and Hickson (2009) identify four factors contributing to the development of the applied communication sub-field: (1) American communication scholars' struggle for disciplinary identity dating to 1914; (2) a drive over the next 60 years among members of what is now the National Communication Association (NCA) to build research-based knowledge of communication; (3) a desire to create knowledge that contributes to the solution to social problems; (4) a commitment to insuring that stakeholders are aware of and can utilize communication scholarship. As Cissna et al. chronicle, the institutionalization of applied communication research in America occurred through a number of concurrent applied projects in the 1970s, including a journal devoted entirely to scholarship on applied communication and with 'applied' in its title.

Over the past two decades, other structures evolved that further institutionalized applied communication research: divisions within professional associations and awards for scholarship; a dedicated journal and special issues of others; conferences and proceedings; edited volumes; graduate programs or emphases; curriculum tracks, individual courses, and textbooks. Examination of national communication association websites around the world reveals scant reference to the field, and only a few international universities offer applied communication degrees. While applied communication research is integral to communication scholarship worldwide, the term seems not to have entered the lexicon outside American scholarship and scholarly institutions.

\section{See also: COMMUNICATION AS A FIELD AND DISCIPLINE}

\section{REFERENCES}

Cissna, K. N., Eadie, W. F., \& Hickson, M. III (2009). The development of applied communication research. In L. R. Frey \& K. N. Cissna (eds.), Handbook of applied communication. Mahwah, NJ: Lawrence Erlbaum, pp. 3-25.

Dempsey, S. E. \& Barge, J. K. (2014). Engaged scholarship and democracy. In L. L. Putnam \& D. K. Mumby (eds.), The SAGE handbook of organizational communication. 3rd edn. Thousand Oaks, CA: Sage, pp. 665-688.

Eadie, W. F. (1982). The case for applied communication research. Spectra, 18(3), 1-2.

Putnam, L. L. (2009). The four faces of engaged scholarship. Keynote address presented at the 7 th Aspen Conference on Engaged Scholarship, Aspen, Colorado, August. 
Seibold, D. R. (2000). Applied communication scholarship: Less a matter of boundaries than of emphases. Journal of Applied Communication Research, 28, 183-187.

Seibold, D. R. (2005). Bridging theory and practice in organizational communication. In J. L. Simpson \& P. Shockley-Zalabak (eds.), Engaging communication, transforming organizations: Scholarship of engagement in action. Cresskill, NJ: Hampton, pp. 13-44.

\section{Appraisal Theory}

JOSEF NERB

Freiburg University of Education

Appraisal theories of emotions offer a systematic linkage between cognitive evaluations of a situation and emotional reactions (see Moors et al. 2013). These theories link the cognitive appraisals of a situation to that person's emotional experiences ( $\rightarrow$ Cognitive Science). For example, the appraisal that a situation is positively relevant for a person is seen as determining positive emotions, whereas the appraisal of negative relevance for a person is regarded as determining negative emotions. Of course, there are additional appraisals and it is assumed that different patterns of appraisals further differentiate emotions. Within appraisal theories, emotions are seen as continuous processes, changing as appraisals are added or revised $(\rightarrow$ Affective Disposition Theories; Affects and Media Exposure; Emotional Arousal Theory).

Some recent theorists postulate a reciprocal causation between cognitive appraisal and emotion. Adopting such a dynamic appraisal-emotion relationship has important implications for analyzing $\rightarrow$ media effects. Nerb and Spada (2001) developed the computational model ITERA for analyzing and predicting media effects including behavioral intentions of the audience assuming a dynamic, bidirectional appraisal-emotion relationship. Using fictitious but realistic newspaper reports about an environmental problem, the authors manipulated attributes determining the agent's responsibility for environmental damage (knowledge about the riskiness of an action; motive of the actor). Manipulating these appraisals of responsibility not only influenced participants' felt anger and sadness but also affected ratings on non-manipulated attributes of the negative event. The effects on those non-manipulated variables were coherent with the overall emotional reactions of the participants. Thus, participants' construals of the situation are consistent with the underlying appraisal pattern for anger.

Based on this research, Kepplinger, Geiss, \& Siebert (2012) have proposed a comprehensive theory regarding the effects of media frames in scandals involving public figures model. Their model characterizes media coverage about damages and transgressions with regard to five aspects: (1) amount of damage caused and (2) agency; (3) involvement of selfish goals or altruistic/common goals ( $\rightarrow$ Goals, Cognitive Aspects of); (4) knowledge about the consequences of the causing behavior; (5) amount of control to act differently. Survey data showed that people either will develop anger and the consistent belief that the public figure is guilty with regard to all five frame components, or will feel sadness and arrive at the opposite conclusion and consistently excuse the public figure concerning all frame components.

\section{See also: AFFECTIVE DISPOSITION THEORIES \\ AFFECTS AND MEDIA EXPOSURE COGNITIVE SCIENCE DMOTIONAL AROUSAL THEORY \\ GOALS, COGNITIVE ASPECTS OF \\ INFORMATION PROCESSING MEDIA EFFECTS}

\section{REFERENCES AND SUGGESTED READINGS}

Kepplinger, H., Geiss, S., \& Siebert, S. (2012). Framing scandals: Cognitive and emotional media effects. Journal Of Communication, 62(4), 659-681.

Moors, A., Ellsworth, P. C., Scherer, K. R., \& Frijda, N. H. (2013). Appraisal theories of emotion: State of the art and future development. Emotion Review, 5(2), 119-124.

Nerb, J. \& Spada, H. (2001). Evaluation of environmental problems: A coherence model of cognition and emotion. Cognition and Emotion, 15, 521-551.

\section{Arab Satellite TV News}

\section{MARWAN M. KRAIDY}

University of Pennsylvania

Arab satellite television emerged in the context of the 1991 Gulf War. Since then, the evolution of the industry has evinced two changes of direction. First, in the 1990s, there was a shift from officially 
sanctioned national broadcasting systems to a process of regional media integration $(\rightarrow$ Communication Law and Policy: Middle East). The second shift occurred around 2000, toward specialization and niche markets. The years 1991, 1996, and 2003 witnessed industry milestones. First, politically connected Saudi entrepreneurs launched the Middle East Broadcasting System (MBC) in London, and the Egyptian government launched the Egyptian Satellite Channel (ESC) in 1991. Then came the launch of $\mathrm{Al}$ Jazeera and the initiation of satellite operations by Lebanese broadcasters LBC and Future TV in 1996. In 2003, Al Arabiya went on the air as a Saudi-financed rival to $\mathrm{Al}$ Jazeera. As of 2007, there were more than 250 Arabic-language, transnational satellite television channels.

Though Arab satellite channels began broadcasting in the 1990s, the policy and technical infrastructure of Arab satellite television had developed over three decades. The Arab satellite organization ARABSAT was established in April 1976 as an organization affiliated with the Arab League. Oil-rich Saudi Arabia bankrolled ARABSAT, and the Saudi capital Riyadh housed ARABSAT's headquarters. First-generation satellites were launched in the 1980s, and several generations have been put into orbit since. In 1998, the Egyptian government, long a political rival of the Saudi royal family for pan-Arab leadership, launched the satellite NILESAT. Pan-Arab broadcasters could also use the European satellite HOTBIRD and still others. In the 1990s, Arab states either removed or stopped enforcing restrictions on satellite dish ownership, and some states developed 'media cities' with financial and labor incentives to national, Arab, and western companies. Dubai leads the way, with other less influential cities operating in Egypt and Jordan.

The combination of satellite technology, war, and economic considerations led to a regionalization of Arab television, aided by the presence of more than 200 million viewers living on a vast stretch of land from Morocco to Iraq and sharing the Arabic language. The new satellite channels attempted at first to replace terrestrial channels with a general format, mixing news and entertainment.

In $\rightarrow$ news, transnationalization led to the 'anywhere but here' news phenomenon, where each channel took the opportunity to criticize all countries and policies except the country in which that channel was based or that financed its operations.
$\mathrm{Al}$ Jazeera is credited with creating a pan-Arab $\rightarrow$ public sphere, and criticized for neglecting local issues specific to countries or communities. The channel occasionally featured dissidents discussing sensitive political topics, but because of the need to retain a transnational audience, a small number of 'big' issues such as the Arab-Israeli conflict and the US occupation of Iraq took the lion's share of news attention, at the expense of local issues.

The most significant genre on Arab news channels was the political talk show $(\rightarrow$ Broadcast Talk). The most famous is Al Jazeera's 'Al-Ittijah Al-Mu'akiss' (The Opposite Direction), a spin-off from $\rightarrow$ CNN's now defunct "Crossfire." Other shows have featured feminists debating clerics, dissidents arguing with regime representatives, and controversial artists defending their work. These talk shows were a dramatic illustration of the variety of opinions aired in Arab public discourse. Specialized satellite channels also attempted to lure niche audiences. This was especially the case with economically oriented channels.

Arab satellite television presents a unique case of a regional media industry developing rapidly both qualitatively and quantitatively, and creating a vibrant and complex regional sphere of information and culture. Relying on a transient and transnational workforce working increasingly on format-based productions destined for the panArab market, and concentrated in Beirut, Cairo, and Dubai, Arab satellite television has established a strong regional, and even global, presence.

\section{See also: $>$ BROADCAST TALK $>\mathrm{CNN}$ \\ COMMUNICATION LAW AND POLICY: MIDDLE EAST DINTERNATIONAL TELEVISION $>$ NEWS $>$ PUBLIC SPHERE $>$ REALITY TV $>$ SATELLITE COMMUNICATION, GLOBAL $>$ SATELLITE TELEVISION}

\section{REFERENCES AND SUGGESTED READINGS}

Ayish, M. I. (1997). Arab television goes commercial: A case study of the Middle East Broadcasting Center. Gazette, 59(6), 473-494.

Boyd, D. A. (1999). Broadcasting in the Arab world: A survey of the electronic media in the Middle East. Ames, IA: Iowa State University Press.

El-Nawawy, M. \& Iskandar, A. (2003). Al-Jazeera: Inside the Arab news network that rattles governments and 
redefines modern journalism. Boulder, CO: Westview Press.

Hafez, K. (2001). Mass media, politics and society in the Middle East. Cresskill, NJ: Hampton Press.

Kraidy, M. M. (2002). Arab satellite television between regionalization and globalization. Global Media Journal, 1(1). At http://repository.upenn.edu/asc papers/186/, accessed July 16, 2014.

Lahlali, M. (2011). Contemporary Arab broadcast media. Edinburgh: Edinburgh University Press.

Rugh, W. (2004). The Arab mass media: Newspapers, radio and television in Arab politics. Westport, CT: Greenwood.

\section{Archiving of Internet Content}

STEVE SCHNEIDER

State University of New York Institute of Technology

KIRSTEN FOOT

University of Washington

Communication scholars interested in new media are increasingly archiving content of the Internet to examine retrospectively content produced and distributed on the web, and the behavior of those producing, sharing, and using the world wide web. New media scholars have begun to find web archives helpful as they seek to understand developments related to the web in a variety of ways. These may involve adapting traditional methods of social research such as content analysis, $\rightarrow$ ethnography, focus groups, $\rightarrow$ surveys, and experiments or developing methods (such as network analysis), hyperlink analysis, and other approaches to structural or phenomenological analyses of the web.

The impetus for web archiving, for both scholarly and historical purposes, dates from the 1980s, as institutions increasingly shifted their records from paper to electronic form. By 1995, web harvesting programs or 'crawlers' were developed, i.e. applications that traverse the web following links to pages, initially from a set of pre-defined seed URLs.

The construction of a web archive and accompanying infrastructure to facilitate scholarly analysis includes four distinct processes. First, the archive creators identify web pages and/or websites to be collected and specify rules for archiving page requisites, such as images, and for following links on archived pages. Next, crawling software is employed to collect the desired web objects. Finally, a system for displaying archived impressions is developed and an interface created to provide access to the archive.

Once objects have been archived, archivists need to address the task of generating and storing metadata at a level of analysis appropriate to the anticipated research. In terms of representativeness, there is growing concern that substantial archives of web content may exclude significant portions of the web - specifically, websites produced outside of North America, Europe, and Asia.

\section{See also: CONTENT ANALYSIS, QUALITATIVE \\ CONTENT ANALYSIS, QUANTITATIVE \\ COPYRIGHT DIGITAL MEDIA, HISTORY OF \\ ETHNOGRAPHY OF COMMUNICATION \\ ONLINE RESEARCH $>$ SURVEY}

\section{REFERENCES AND SUGGESTED READINGS}

Brugger, N. (2013). Web historiography and internet studies: Challenges and perspectives. New Media \& Society 15, 752-764.

Schneider, S. \& Foot, K. (2005). Web sphere analysis: An approach to studying online action. In C. Hine (ed.), Virtual methods: Issues in social science research on the Internet. Oxford: Berg.

Toyoda, M. \& Kitsuregawa, M. (2012). The history of web archiving. Proceedings of the IEEE, 100, Special Centennial Issue, 1441, 1443, May 132012 doi: 10.1109/JPROC.2012.2189920. At http://ieeexplore. ieee.org/stamp/stamp.jsp?tp=\&arnumber $=6182575$ \&isnumber=6259910, accessed July 15, 2014.

\section{Art as Communication}

\section{MICHAEL GRIFFIN \\ Macalester College}

In modern Western culture, art has increasingly been defined as an elite sphere of activity distinct from broader notions of social communication. Since Kant and Hume, discriminations of sensory beauty and 'delicacy of taste' have been invoked in judgments of aesthetic value that separate those forms of communication that qualify as art from 
those that do not. Yet in most cultures for most of human history, the creation of art has been socially organized, central to the communication of shared religious beliefs, mythic understandings of the world, and social relations. Indeed, the rise of technologies of mass communication were theorized in the twentieth century in terms of their relationship to the traditional arts, and media content often characterized the product of newly emerging $\rightarrow$ 'culture industries' $(\rightarrow$ Printing, History of) as 'popular arts.'

Modernist definitions of art as non-utilitarian and honorific have tended to separate art activity from religion, education, craft, and other forms of functional communication in favor of an emphasis on individual self-expression, formalism, emotional evocation, or representations of the mysterious, the subconscious, or the ineffable. This has involved a movement away from the reaffirmation of common cultural knowledge and shared community values toward the marking of elite knowledge and memberships. Thus, the main recent sense of the word 'art' has referred to 'original' or 'unique' expression, and its communicative effect has shifted from the conscious articulation of social knowledge and cultural heritage to the idea of innovative individual creativity. Modern art has even been described as a "project of negation," that is, the progressive breaking free from established cultural practices, generating "a growing canon of prohibitions: representation, figuration, narration, harmony, unity" (Bernstein 2001, 21).

However, beyond the parameters of modern history and modernist aesthetic philosophy, the term art is more likely to be applied to a wide range of creative production that reflects and projects social relations, political power, and cultural beliefs and practices. As such, it encompasses ancient architectural structures, statues, obelisks, bas-reliefs, pottery, masks, and funerary arts, as well as the conventional fine arts of poetry, literature, drama, music, painting, and prints. These and other forms of artistic creativity have functioned as powerful social communication in virtually all cultures, reproducing established cultural heritage and the ideological assumptions of those social, economic, and political formations that support, or require, their creation $(\rightarrow$ Culture: Definitions and Concepts; Cultural Studies). Studies in the sociology and social history of art identify such artistic production as the communication of prevalent ideas in a particular culture at a specific point in history - the result of the institutional and organizational contexts in which art production occurs.

Berger (1972), building from Benjamin (1968), makes a similar argument about the transformation of art made to fulfill a particular role in a specific place and time, to industrial objects reproduced and proliferated in multiple forms and contexts. The communicational function of paintings shifts when they are lifted from their original context and reproduced in advertising or on T-shirts ( $\rightarrow$ Visual Culture).

Art's function as communication is highly dependent upon its specific social use within particular institutional and organizational networks. For European and American sociologists in the twentieth century, the fragmentation of art forms and the rise of mass-mediated popular culture effaced distinctions between art and craft at the same time as it reinforced the notion of 'fine art' as a symbolic indicator of social status. Sociologists of art foregrounded the collective nature of artistic production, consumption, and valuation, pointing to the meaning of artistic activity for the social communication of groups (Becker 1982). The cooperative creation of artworks (in art studios, camera clubs, or by film crews), the viewing, reception, and purchase of artistic products by audiences and networks of fans or connoisseurs, and the definition and evaluation of art itself by educational institutions, galleries, and museums, all involve the sharing and exercise of cultural assumptions and communication practices within social groups.

At the same time, the capacity of figural and pictorial art to provide literal mappings and reflections of the world facilitated the descriptive power of visual media, and by extension its persuasive and manipulative potential ( $\rightarrow$ Photojournalism; Propaganda, Visual Communication of).

\footnotetext{
See also: C CINEMA CULTURAL STUdies

CULTURE: DEFINITIONS AND CONCEPTS

CULTURE INDUSTRIES DESIGN D DIGITAL IMAGERY $>$ ICONOGRAPHY $>$ PHOTOGRAPHY PHOTOJOURNALISM P PRINTING, HISTORY OF PROPAGANDA, VISUAL COMMUNICATION OF REALISM IN FILM AND PHOTOGRAPHY $>$ SIGN
} 
TASTE CULTURE VISUAL COMMUNICATION

VISUAL CULTURE VISUAL REPRESENTATION

\section{REFERENCES AND SUGGESTED READINGS}

Baxandall, M. (1972). Painting and experience in fifteenth-century Italy: A primer in the history of pictorial style. Oxford: Clarendon Press.

Becker, H. S. (1982). Art worlds. Berkeley, CA: University of California Press.

Benjamin, W. (1968). The work of art in the age of mechanical reproduction. In $\mathrm{W}$. Benjamin, Illuminations (ed. and intro. H. Arendt, trans. H. Zohn). New York: Schocken Books.

Berger, J. (1972). Ways of seeing. London: Penguin.

Bernstein, J. (ed.) (2001). The culture industry: Selected essays on mass culture. London: Routledge.

Wolff, J. (1993). The social production of art, 2nd edn. London: Palgrave Macmillan.

\section{Asia: Media Systems}

CHERIAN GEORGE

Hong Kong Baptist University

The 25-plus countries of south, east, and southeast Asia possess media systems that are extremely diverse. In political terms, the region comprises some of the world's largest multi-party democracies (India, Indonesia), but also most of its remaining one-party communist states (China, Vietnam, Laos) as well as a couple of hereditary absolutist systems (North Korea, Brunei). Market conditions are equally varied. While newspapers have been in dramatic decline in much of the developed West, the industry is lucrative and still growing in many of Asia's booming cities. However, there are also several smaller and poorer Asian markets (Bhutan, Cambodia, and Timor Leste, for example) where media sustainability is a major challenge even in their main cities, let alone the rural hinterland $(\rightarrow$ Media Economics).

\section{Communalities and Differences}

Any analysis of Asian media should take into account the profound social and political divisions within countries. Most countries have a cosmopolitan elite with consumption habits similar to the cities of the advanced industrial world, but also communities struggling with poverty, low literacy and lack of communications connectivity. In many authoritarian systems, government control is usually not total, creating a bifurcated media space with strict regulation of print and broadcast media but relative freedom online. Mainstream commercial newspapers - typically the focus of the literature on media systems - are, in many Asian countries, confined to world of the urban elites and middle classes. Government broadcasters and community radio are still the main media in rural hinterlands. In countries with severe restrictions on press freedom (China, Vietnam, Malaysia, and Singapore), the Internet has emerged as a qualitatively distinct ecosystem.

The most influential suggestion of commonality across this vast region came in the 1990s, when analysts flirted with the notion of an 'Asian way' - referring to an approach to democracy supposedly informed by 'Asian' values of harmony, community, consensus, and respect for authority. Some Asian governments suggested to journalists that these values were rooted in Asian cultural norms; and that urgent development challenges were better addressed by cooperating with a nation's leaders than through a Westernstyle adversarial press $(\rightarrow$ Journalists' Role Perception). The thesis was criticized for its selective and self-serving reading of the cultures and traditions of a continent with several millennia's worth of practical and philosophical grappling with questions of power, communication and the good society. At best, the Asian way was seen as a normative vision of some Asian leaders, not necessarily shared by most Asian journalists and bearing little connection with the actual dynamics of media-state contestation on the ground.

While Asian journalists operate in a very wide diversity of political, economic, cultural and organizational contexts, recent studies suggest that there is considerable normative agreement around what can be described as universal principles of professional journalism $(\rightarrow$ Professionalization of Journalism). The notion that journalists should help ordinary citizens by giving them reliable information and keeping an eye on those in power appears to be widely shared. Even in China, frustration with rampant corruption has given the watchdog role greater moral legitimacy than the official communist precept of media as propaganda mouthpieces of the Party. 


\section{Communication Freedom in Asia}

Over the decades, there have been advances in media freedom, driven by various forces ( $\rightarrow$ Freedom of Communication). Some countries liberalized their media regimes as part of major democratic reforms (South Korea since 1988, Indonesia since 1998, Myanmar since 2012). In line with international human rights norms, several countries have decriminalized defamation and introduced freedom of information laws or regulations. Even in states where there has been no great appetite for media liberalization, technological and economic transformations have widened people's choices. In the 1990s, $\rightarrow$ cable and $\rightarrow$ satellite television broke the stranglehold that government broadcasters used to exercise. This was followed by the Internet, which has allowed $\rightarrow$ news and opinion to circulate more freely.

Despite these positive changes, Asia remains a laggard in media freedom. Freedom House rates half the territories in the region as having 'not free' media, with only two (Japan and Taiwan) placed in the 'free' category. Violence against media workers and the impunity enjoyed by its perpetrators are a special problem, with Afghanistan, Pakistan and the Philippines rated among the least safe places in the world for journalists ( $\rightarrow$ Violence against Journalists).

Asian media dynamics cannot be fully understood without also attending to non-state actors. Mob action has been an increasingly important factor. Intolerant groups who are prepared to harass and physically attack news media professionals and premises are a greater threat to media freedom than government restrictions in several countries. This can be thought of as the dark side of 'people power' and shows that the growing role of $\rightarrow$ public opinion, when untempered by civic norms, need not have a liberal or progressive effect. These forces include the religious right (in Bangladesh, India, Indonesia, Malaysia, Pakistan) and hypernationalism (in China). Such mob action, although seemingly spontaneous, is usually instigated and supported by factions within the political elite.

\section{Media Markets in Asia}

Perhaps the single most important trend in Asian media systems has been the rise of the market as the dominant mechanism that shapes who gets to say what to whom. In societies where the media used to be little more than government mouthpieces, the entry of commercial considerations has been welcomed. In China, for example, newspapers mandated to pursue profits have had to be more responsive to public wants and needs. However, as predicted by critical perspectives in media studies, the market has not always served the public interest. The main wave of commercialization occurred in the 1990s, with the arrival of cable and satellite television technologies. This coincided with a global ideological climate of neoliberalism, which encouraged untrammeled profit-making facilitated by strong pro-business governments, while negating any role for independent public institutions in safeguarding the public interest $(\rightarrow$ Markets of the Media; Diversification of Media Markets).

Accordingly, Asian media systems are strikingly devoid of independent public service broadcasting. Japan's NHK comes closest to fulfilling that role. Even in relatively democratic states such as India and Indonesia, governments retain control over their respective national broadcasters $(\rightarrow$ Public Broadcasting Systems). As for the private sector, the region lacks independent regulators able to ensure that licenses are allocated according to transparent public-interest criteria. Instead, freeto-air and pay-TV licenses are in several countries (Bangladesh, Cambodia, Malaysia) given to proxies and cronies of ruling party politicians. In several other countries (Indonesia, Mongolia, the Philippines), TV channels have been acquired by owners who use them to further their business or political ambitions.

In Asia's newspaper industry, commercialization is associated with an erosion of editorial integrity, as professional journalistic considerations lose ground to the priorities of marketing departments or owners' private agendas. While journalism in Asia has a rich history - playing a heroic part in the independence struggles and democratic revolutions of several nations - the profession is generally ill-equipped to stand up to market pressures. In many countries, wages are too low to support a family, pressuring journalists to take on second jobs. In several countries, some reporters engage in 'envelope' journalism - receiving cash from newsmakers. This practice of paid news has been institutionalized by some Indian newspaper managements, who have taken to selling news space to 
election candidates ( $\rightarrow$ Commercialization: Impact on Media Content).

\author{
See also: CABLE TELEVISION \\ $\checkmark$ COMMERCIALIZATION: IMPACT ON MEDIA \\ CONTENT DIVERSIFICATION OF MEDIA \\ MARKETS FREEDOM OF COMMUNICATION \\ DOURNALISTS' ROLE PERCEPTION M MARKETS \\ OF THE MEDIA $>$ MEDIA ECONOMICS $>$ NEWS \\ PROFESSIONALIZATION OF JOURNALISM \\ PUBLIC BROADCASTING SYSTEMS PUBLIC \\ OPINION $>$ SATELLITE TELEVISION \\ VIOLENCE AGAINST JOURNALISTS
}

\section{REFERENCES AND SUGGESTED READINGS}

Bromley, M. \& Romano, A. (eds.) (2005). Journalism and democracy in Asia. London: Routledge.

Freedom House (2013). Freedom of the Press 2013. At http://www.freedomhouse.org/report/freedompress/freedom-press-2013, accessed July 25, 2014.

International Federation of Journalists. Asia Pacific. At http://asiapacific.ifj.org/en, accessed July 25, 2014.

Open Society Foundations. Mapping Digital Media reports. At http://www.opensocietyfoundations.org/ projects/mapping-digital-media, accessed July 25, 2014.

WAN-IFRA (2012). World Press Trends Report 2012. Darmstadt: World Association of Newspapers and News Publishers.

Weaver, D. H. \& Willnat, L. (eds.) (2012). The global journalist in the 21st century. London: Routledge.

\section{Attending to the Mass Media}

\author{
MARK SHEVY \\ Northern Michigan University \\ ROBERT HAWKINS \\ University of Wisconsin-Madison
}

Mass communication's impact has been shown at an individual level and in society at large, yet all mass communication must pass through the same narrow gateway before having these varied effects ( $\rightarrow$ Media Effects). Unless people receive mass communication through their eyes and ears (or sometimes touch), and cognitively process it, it is powerless. Attention is a central factor in understanding what it means to watch television and videos, use the Internet, listen to the radio, or read the newspaper. Although attention is a part of receiving and processing messages from all types of media, much of what we know comes from research on attending television and video.

In studies of mass communication and cognition ( $\rightarrow$ Cognitive Science), attention refers to a state of cognitive focus on a particular stimulus. As such, it is the first step in prominent media psychology models and theories $(\rightarrow$ Information Processing; Learning and Communication; Social Cognitive Theory). Looking and listening are external manifestations of attention, not the attention itself. Attention thus involves directing sensory organs toward the acquisition of messages and other stimuli and allocating cognitive resources toward processing them. A television viewer must first focus on a character before information about that character can be cognitively decoded, comprehended, stored, and remembered.

Although attention as cognitive focus sounds like a singular construct, there are in fact two separate aspects: (1) where cognitive focus is directed (an either/or matter) and (2) the amount of effort directed to it. For the most part, questions about where one focuses and the amount of cognitive resources applied are different, despite carrying the same label of 'attention.' Researchers cannot directly observe the focus of a person's cognition, so attention is operationalized through indirect measures such as when and how long viewers look at a screen, what part of the screen they look at, cardiac deceleration, depressed alpha power in electroencephalogram (EEG) monitoring, and memory of message information ( $\rightarrow$ Operationalization; Physiological Measurement).

Attention can be initiated in two ways. The first is an involuntary response to some feature of the message. An automatic biological drive to attend to new or changing stimuli results in an orienting response (OR) that focuses cognitive resources on the stimuli without conscious control. For example, if a radio playing in the background at a workplace suddenly emits a loud noise, people may automatically shift their attention from their work to the radio for a moment. The Limited Capacity Model of Motivated Mediated Message Processing (LC4MP; Lang 2009) states that formal features and content that activate motivational systems 
(basic responses to positive stimuli such as food or unpleasant stimuli such as danger) may also elicit involuntary attention.

The second way is initiation by the viewer/listener as a controlled and strategic process (though perhaps overlearned and automatic). People can consciously try to attend to a stimulus, and they can learn strategies to allocate more attention to a medium when the most useful information is presented. For example, children's looks at the screen are often based upon comprehensibility. By the age of 2, toddlers learn which formal features (certain sounds, motions, edits) are associated with comprehensible content, and they use those features as attention cues (Anderson \& Kirkorian 2006). Over time, attentional responses based on this learning can become essentially automatic (Lorch et al. 1979).

The theorized purpose for attentional processes is to avoid overloading the brain with information overload. The brain has a limited capacity for processing information, and attention determines which information will receive preference for cognitive resources.

Special research topics in attending to media investigate the development of attention strategies in infants and children, how cognitive resources are allocated, attentional inertia (the phenomenon in which the longer a look has lasted, the more likely it will continue), types of look lengths (40 percent of looks at television are 1.5 seconds or less), and effects of attention such as comprehension and learning. Some research also considers how various media (television, web pages, radio, newspapers, etc.) may have similar or different influences on attentional strategies and processes.

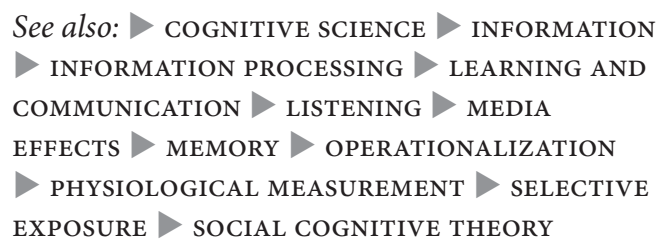

\section{REFERENCES AND SUGGESTED READINGS}

Anderson, D. R. \& Kirkorian, H. L. (2006). Attention and television. In J. Bryant \& P. Vorderer (eds.), Psychology of entertainment. Mahwah, NJ: Lawrence Erlbaum, pp. 35-54.
Lang, A. (2009). The limited capacity model of motivated mediated message processing. In R.L. Nabi \& M.B. Oliver (eds.), The sage handbook of media processes and effects. Thousand Oaks, CA: Sage, pp. 193-204.

Lorch, E. P., Anderson, D. R., \& Levin, S. R. (1979). The relationship of visual attention to children's comprehension of television. Child Development, 50, pp. $722-727$.

\section{Attitude-Behavior Consistency}

\section{NANCY RHODES}

Ohio State University

Does knowing a person's $\rightarrow$ attitude allow one to predict that person's behavior? Historically, attitudes were thought to be an important topic to study because early researchers assumed that attitudes are strongly related to behavior. However, work questioning the assumption that attitudes guide behavior began to accumulate. An influential paper published by Allan Wicker in 1969 found only a weak relationship. The resulting controversy fostered a somewhat contentious climate that nonetheless produced an abundance of creative ideas about the relationship of attitudes to behavior.

One response to the concern that attitudes were not predictive of behavior was the observation that behaviors and attitudes are often measured at different levels of specificity $(\rightarrow$ Measurement Theory). Attitudes are typically measured as general assessments of attitude objects, whereas behavioral measurement is typically an observation or report of a single opportunity to engage in an action. Attempting to correlate one very specific construct with another construct that is vague usually will tend to reduce the observed correlations. Fishbein and Ajzen (1974) suggested measuring the attitude toward performing the behavior at a particular point in time. Asking the attitude question with that level of specificity improved the ability to predict behavior. Fishbein \& Ajzen later went on to refine their ideas into models known as the $\rightarrow$ 'theory of reasoned action' and the $\rightarrow$ 'theory of planned behavior'.

Strongly held attitudes are more predictive of behavior than attitudes that are held more weakly. One way to think about strong attitudes is to 
consider how quickly an attitude judgment comes to mind upon encountering an attitude object. Russell Fazio (1990) and his colleagues were primarily concerned with attitude accessibility, or how easily attitudes are activated from $\rightarrow$ memory. According to this research, when attitudes are highly accessible, they are quickly activated in memory, and thus are more likely to be acted upon than less accessible attitudes. These accessible attitudes are activated immediately upon encountering an attitude object without conscious effort and thus more predictive of behavior than less accessible attitudes.

An additional aspect of attitude strength is the confidence in the correctness of one's attitudes. Attitude confidence has recently been investigated in an extension of the $\rightarrow$ Elaboration Likelihood Model. This meta-cognitive model has been used in investigations of persuasion (Petty, Briñol, \& Tormala 2002) and the attitude-behavior relationship (Bergkvist 2009). Findings generally show that when people are more confident in their attitudes and in the thoughts they have in reaction to a persuasive message, their attitudes are more predictive of their behavior. Finally, an additional moderator of the attitude-behavior relationship is the strength of the situation in which the behavior might occur. Just as attitudes can be described as being strong or weak, situations also vary in strength. A strong situation is one in which the range of acceptable behaviors is very narrow, whereas a weak situation has a wider range of potential behaviors. Research indicates that attitudes are more predictive of behaviors when the situation is weak than when the situation is strong: Strong situations constrain behavior to the extent that all people behave similarly regardless of their attitudes, whereas in a weak situation, where the prescribed behavior is not clear, attitudes are far more likely to guide one's choice of action.

The attitude-behavior relation can also occur in the reverse direction: behavior can affect attitudes. Decades of research investigating $\rightarrow$ cognitive dissonance theory and self-perception theory demonstrated that engaging in counter-attitudinal behavior is likely to change one's attitudes to be consistent with the behavior.

See also: attitudes $>$ COgNitive Dissonance THEORY \ ELABORATION LIKELIHOOD MODEL
INFORMATION PROCESSING $>$ MEASUREMENT THEORY $>$ MEMORY $>$ PERSUASION $>$ PLANNED BEHAVIOR, THEORY OF $>$ REASONED ACTION, THEORY OF

\section{REFERENCES AND SUGGESTED READINGS}

Bergkvist, L. (2009). The role of confidence in attitudeintention and beliefs-attitude relationships. International Journal of Advertising: The Quarterly Review of Marketing Communications, 28(5), 863880, doi:10.2501/S026504870920093X .

Fazio, R. H. (1990). Multiple processes by which attitudes guide behaviour: The MODE model as an integrative framework. In M. P. Zanna (ed.), Advances in Experimental Social Psychology, 23, 74-109.

Fishbein, M. \& Ajzen, I. (1974). Attitudes toward objects as predictors of single and multiple behavioral criteria. Psychological Review, 81, 59-74.

Petty, R. E., Briñol, P., \& Tormala, Z. L. (2002). Thought confidence as a determinant of persuasion: The self-validation hypothesis. Journal of Personality and Social Psychology, 82(5), 722-741, doi:10.1037/0022-3514.82.5.722.

Wicker, A. W. (1969). Attitude versus actions: The relationship of verbal and overt behavioral responses to attitude objects. Journal of Social Issues, 25(4), 41-78.

\section{Attitudes}

\section{DAVID R. ROSKOS-EWOLDSEN}

Ohio State University

Attitudes are defined as a hypothetical construct involving the evaluation of some object. They are hypothetical constructs because they cannot be directly observed but are measured indirectly. Attitudes also involve evaluations of how positively or negatively a person judges something. They are directed toward some object or thing such as Diet Coke, ideas such as democracy, individuals, groups of people, and so forth. People can have ambivalent attitudes. Attitude ambivalence refers to situations where people simultaneously have both positive and negative evaluations of an object. Another development in thinking about attitudes involved the functions that attitudes serve for people.

The early and extremely influential tripartite model of attitudes held that attitudes comprised three elements: affective, behavioral, and cognitive. The affective component of an attitude is the 
emotional or visceral reaction to the attitude object. The 'yuck' reaction to a cockroach involves the affective component of the attitude. The behavioral component of an attitude, historically considered the most important one, refers to the actions taken in regard to the attitude object. Research has shown that people's behavior influences their attitudes. Dissonance theory predicts that if people engage in behavior that is inconsistent with their attitudes, they may change their attitudes to be consistent with the behavior $(\rightarrow$ Attitude-Behavior Consistency; Cognitive Dissonance Theory). The cognitive component encompasses people's thoughts and beliefs related to the attitude object. The beliefs about an object will influence what a person's attitude is toward the attitude object. Likewise, attitudes can influence the beliefs that people develop by biasing how information is processed.

An important distinction emerging in the study of attitudes involves explicitly versus implicitly measured attitudes. This distinction arose from research demonstrating that people's explicitly measured attitudes may reflect their motivation not to express an undesirable attitude such as a racist attitude. Implicit measures of attitudes involve measuring a person's attitude without the person being aware that the attitude is being measured so that the person is not motivated to "hide" the undesirable attitude.

\section{See also: ADVERTISING AS PERSUASION \\ ATTITUDE-BEHAVIOR CONSISTENCY \\ COGNITIVE DISSONANCE THEORY \\ $\checkmark$ ELABORATION LIKELIHOOD MODEL \\ $\checkmark$ EXTENDED PARALLEL PROCESS MODEL \\ $\checkmark$ INTERPERSONAL ATTRACTION MEMORY \\ $>$ PERCEPTION $>$ PERSUASION $>$ POLITICAL PERSUASION}

\section{REFERENCES AND SUGGESTED READINGS}

Albarracin, D., Johnson, B. T., \& Zanna, M. P. (eds.) (2005). The handbook of attitudes. Mahwah, NJ: Lawrence Erlbaum.

Dillard, J. P. \& Shen, L. (eds.) (2013). The Sage handbook of persuasion: Development in theory and practice. Los Angeles: Sage.

Eagly, A. H. \& Chaiken, S. (1993). The psychology of attitudes. Fort Worth, TX: Harcourt Brace Jovanovich.

\section{Audience Research}

JAMES G. WEBSTER

Northwestern University

Audience research denotes the systematic study of any audience for any purpose. In practice, it usually means describing and analyzing patterns of media use, often for some commercial or administrative purpose. Such research became commonplace in the early twentieth century as new forms of advertiser-supported media, like radio, were introduced. Contemporary audience research uses a wide range of theories and methods, which can be organized using the familiar labels of theoretical vs applied, quantitative vs qualitative, and, somewhat less conventionally, custom vs syndicated research $(\rightarrow$ Exposure to Communication Content).

Theoretical audience research operates on two conceptual levels: micro and macro. The former tends to look at audiences from the 'inside out,' adopting the perspective of an individual audience member. Of theoretical interest are the motivations behind media use, the stimuli that command attention ( $\rightarrow$ Attending to the Mass Media), and how media are used in everyday life. This perspective is common in psychology and $\rightarrow$ cultural studies. Macro-level research tends to look at audiences from the 'outside in, attempting to understand their characteristics and behaviors in the aggregate. This perspective sees audiences as markets, publics, and/or networks and often draws on theories in sociology and $\rightarrow$ marketing ( $\rightarrow$ Markets of the Media).

Applied audience research provides information that can be acted upon by institutions. Since the early days of radio, advertisers have demanded surveys to authenticate the size and composition of audiences. This gave rise to audience "ratings" research, which has become essential to the operation of advertiser-supported media throughout much of the world, e.g. the Nielsen Ratings. Newer platforms, like the web and social media, now collect enormous amounts of data which are used for many applied purposes, such as monitoring visitors, assessing engagement, and making recommendations.

Quantitative research methods are common $(\rightarrow$ Quantitative Methodology). Audience ratings companies use probability sampling $(\rightarrow$ Sampling, 
Random) and $\rightarrow$ surveys to estimate the audiences for an ever-growing number of media (e.g., radio, television, movies; $\rightarrow$ video games, mobile, Internet, etc.). Very large, nonrandom samples or panels are also used. For example, digital technologies that produce a record of their use (e.g., servers or digital set-top boxes) offer the prospect of survey-like behavioral data based on a census rather than a sample. Theorists and practitioners also assess the effectiveness of media with physiological measures like eye-movements, and experimental designs executed on the web, called "2A/B testing" ( $\rightarrow$ Media Effects). Qualitative methods ( $\rightarrow$ Qualitative Methodology), sometimes called audience ethnographies, include focus groups, unstructured interviews, and participant observation.

Custom research is tailor-made to serve a particular purpose. Much academic audience research intended for scholarly journals is, in that sense, 'customized.' Media organizations also do research for their own internal consumption. TV studios will, for example, conduct focus groups to assess audience reactions to new programs. Industry-commissioned studies designed to serve client interests can be quite useful internally, but for outsiders they often lack the apparent objectivity of syndicated research.

Syndicated audience research is a standardized research product that is sold to multiple subscribers. It plays an important role in media industries because its costs can be distributed across many buyers and it provides a credible, 'third-party' accounting of audiences independent of the media or advertisers. Measurement companies in the US and much of the world record audience behaviors using a variety of techniques, including diaries, servers, and 'people-meters.' These data are processed and packaged into different reports that constitute a "currency" used to buy and sell audiences.

Because of its pivotal role in the operation of media industries, syndicated research has been the target of critics, who generally voice one of three concerns. The first questions the accuracy of the data in the face of continued audience fragmentation. The second argues for measuring things other than exposure. The third poses more existential questions about the ability of media measurement to reshape audiences and commercial culture.
See also: ADVERTISING ATTENDING TO THE MASS MEDIA > CULTURAL STUDIES D EXPOSURE TO COMMUNICATION CONTENT $>$ MARKETING MARKETS OF THE MEDIA $>$ MEDIA EFFECTS OBSERVATION > PUBLIC OPINION $>$ PUBLIC OPINION POLLING $>$ QUALITATIVE METHODOLOGY QUANTITATIVE METHODOLOGY SAMPLING, RANDOM $>$ SURVEY $>$ VIDEO GAMES

\section{REFERENCES AND SUGGESTED READINGS}

Gunter, B. (1999). Media research methods: Measuring audiences, reactions and impact. London: Sage.

Hartmann, T. (2009). Media choice: A theoretical and empirical overview. New York: Routledge.

Napoli, P. M. (2011). Audience evolution: New technologies and the transformation of media audiences. New York: Columbia University Press.

Turow, J. (2012). The Daily You: How the new advertising industry is defining your identity and your worth. New Haven, CT: Yale University Press.

Webster, J. G. (2014). The marketplace of attention: How audiences take shape in an age of digital media. Cambridge, MA: MIT Press.

Webster, J. G., Phalen, P. F., \& Lichty, L. W. (2014). Ratings analysis: Audience measurement and analytics, 4th edn. New York: Routledge.

\section{Audience Segmentation}

\section{RENÉ WEBER}

University of California, Santa Barbara

Audience segmentation describes the process of partitioning mass audiences into smaller and smaller segments. It is considered as an inevitable outcome of competition in media markets ( $\rightarrow$ Audience Research; Consumers in Media Markets; Diversification of Media Markets; Markets of the Media). Hence, audience segmentation is expected to be stronger in highcompetition media environments.

The concept has been introduced to describe changes in the concept of an audience through the transition from old to new media environments. McQuail (1997) summarizes the concept of audience segmentation by means of four models that represent different stages in the transition: (1) The unitary model (in the 1950s), when TV viewers had no ability to select a program, because there was only one channel available 
( $\rightarrow$ Exposure to Television); (2) the pluralism model (in the 1970s and 80s) with a status of 'limited diversification' of TV channels; (3) the coreperiphery model (in the 1980s and 90s) where the multiplication of channels in many television markets made it possible that specific (special interest) channels had specific audiences; (4) the breakup model in which no core audience exists any more.

McQuail's four stages can be easily transferred to other traditional mass media such as radio and print. However, applying McQuail's models to new, interactive media, like the Internet or $\rightarrow$ video games, is more difficult $(\rightarrow$ Exposure to the Internet). In these media environments users generate their own content and audience segmentation addresses both the free selection of specific media platforms and the generation of, and response to, individualized content. Hence, one might add a fifth model: the individualization model', which defines the highest possible degree of audience segmentation.

A closely related concept to audience segmentation is that of audience polarization (Webster \& Phalen 1997). Audience polarization is defined as the tendency of individuals to move to the extremes of either consuming or avoiding some class of media content. There is also empirical evidence for a modest audience polarization. This tendency, however, is still mainly driven by the fact that many TV channels are still not available to all audiences.

See also: D AUDIENCE RESEARCH CONSUMERS IN MEDIA MARKETS D DIVERSIFICATION OF MEDIA MARKETS DXPOSURE TO TELEVISION $>$ EXPOSURE TO THE INTERNET MARKETS OF THE MEDIA SEGMENTATION OF THE ADVERTISING AUDIENCE $>$ VIDEO GAMES

\section{REFERENCES AND SUGGESTED READINGS}

McQuail, D. (1997). Audience analysis. Thousand Oaks, CA: Sage.

Webster, J. G. (2005). Beneath the veneer of segmentation: Television audience polarization in a multichannel world. Journal of Communication, 55(2), 366-382.

Webster, J. G. \& Phalen, P. F. (1997). The mass audience: Rediscovering the dominant model. Mahwah, NJ: Lawrence Erlbaum.

\section{Audiences, Female}

KAREN ROSS

Northumbria University

Notions of 'the audience' have changed significantly over the past decades, but issues of gender continue to have relevance. Early studies of audiences in the 1930s suggested that in general terms, audiences were regarded as 'mass' and passive, forever in thrall to the propagandist tendencies of governments and big business ( $\rightarrow$ Propaganda). Decades later, audiences were understood as active 'users' of media for their own 'gratifications' ( $\rightarrow$ Uses and Gratifications). Some contemporary thinking shifted again so that the very notion of audience was dismissed in favor of seeing media consumers as atomized individuals, no longer sharing anything as communities of viewers or listeners. Instead, individuals were now to be seen to be both using and producing media ('produsage') as active agents of their own media behavior.

Although research on the female audience spans more than half a century, it was, arguably, the interest of (women) researchers who wanted to explore women's viewing behaviors as specifically gendered acts which marked a turning point during the late 1970s and early 1980s. Three studies of significance in this period were those of Dorothy Hobson (1982), Janice Radway (1984), and Ien Ang (1985), all of which showed the complex relationships which women have to genres such as soaps and romantic fiction. Current researchers have been keen to credit audiences with sophisticated deconstructive and interpretive skills, understanding their viewing behaviors and pleasures as forms of active engagement rather than passive dislocation. Some scholars have suggested that $\rightarrow$ genres such as soaps are themselves subversive genres, since the staple ingredients infidelity, casual sex, unintended pregnancies, divorce, domestic violence, petty crime, and, more recently, storylines about sexuality - are directly antithetical to both the socially acceptable norms of romantic love contained within the domesticated and heterosexual marriage contract, but also the acceptable norms of feminine behavior.

Historically, the principal focus for much academic study of women and film has been textual analysis, and this strand of representation studies has been complemented, in more recent times, by 
a focus on films made by women directors. Work in the 1980s and 1990s mostly focused on women as audiences for film, demonstrating, as with soap audiences, the multiplicity of readings that audiences could bring to a single cultural product, as well as to an entire genre such as the 'woman's film, identifying the importance of historical specificity as well as ethnic background in understanding different responses to texts $(\rightarrow$ Ethnicity and Exposure to Communication). Jacqueline Bobo's (1995) study of African-American women showed the ways in which the practice of reading, both novels and films, could be empowering by placing the female spectator at the center of the analysis in ways which give her importance in her own right, as possessing agency, rather than being simply 'positioned' by the text.

The ways in which $\rightarrow$ advertising influences girls' and women's sense of self-worth through the representation of women and women's bodies in magazines have received considerable and enduring scrutiny over the past few decades ( $\rightarrow$ Advertising Effectiveness). Most of this work suggests that magazines work to the detriment of their readers by perpetuating heterosexist norms about appropriate forms of femininity, causing dissatisfaction among women (readers). While much audience research is situated within a white western paradigm, a number of important studies look beyond the Anglophone world, often showing that irrespective of the traditional norms of 'sanctioned' femininity associated with a particular country, young women may still aspire to the version of white bodily perfection promoted by global (fashion) advertising.

The rapid developments in information and communication technologies (ICTs) mean that we have to rethink what it means to be an audience, including a gendered audience, and consider the (potential, at least) shifts in power between the audience and the artifact $(\rightarrow$ Technology and Communication). Although the initial take-up of the Internet was decidedly male, a number of studies now suggest that women are the fastestgrowing group of Internet users, especially in relation to $\rightarrow$ social media and fan sites $(\rightarrow$ Exposure to the Internet).

See also: $>$ ADVERTISING $>$ ADVERTISING EFFECTIVENESS $>$ AUDIENCE RESEARCH

$>$ CULTURAL STUDIES $>$ ESCAPISM $>$ ETHNICITY
AND EXPOSURE TO COMMUNICATION

ETHNOGRAPHY OF COMMUNICATION

EXPOSURE TO THE INTERNET $>$ FEMINIST

MEDIA $>$ GENRE $>$ MASCULINITY AND MEDIA

$>$ PARASOCIAL INTERACTIONS AND

RELATIONSHIPS $>$ PROPAGANDA $>$ SOCIAL MEDIA

$>$ TECHNOLOGY AND COMMUNICATION D USES

AND GRATIFICATIONS

\section{REFERENCES AND SUGGESTED READINGS}

Ang, I. (1985). Watching Dallas: Soap opera and the melodramatic imagination. London: Methuen.

Bobo, J. (1995). Black women as cultural readers. New York: Columbia University Press.

Hobson, D. (1982). Crossroads: The drama of a soap opera. London: Methuen.

Mulvey, L. (1975). Visual pleasure and narrative cinema. Screen, 16(3), 6-19.

Radway, J. (1984). Reading the romance: Women, patriarchy and popular literature. Chapel Hill, NC: University of North Carolina Press.

Ross, K. (ed.) (2012). The handbook of gender, sex and media. Oxford: Wiley-Blackwell.

Thornham, S. (2012). What if I had been the hero? Investigating women's cinema. London: British Film Institute.

\section{Australia: Media System}

PETER PUTNIS

University of Canberra

The Australian Constitution gives the federal government responsibility for the regulation of "postal, telegraphic, and other like services." Under this provision it also has responsibility for the regulation of all broadcasting and telecommunications in Australia. There are no press laws requiring newspaper licensing. The federal government's power over the press is limited to its general corporate affairs responsibilities and foreign investment. There is also no constitutional provision that explicitly guarantees freedom of the press. Australia has maintained the English tradition that freedom of speech is adequately protected by common law ( $\rightarrow$ Freedom of Communication; Freedom of the Press, Concept of).

Australia's first newspaper, the Sydney Gazette, which commenced publication in 1803, was published by the authority of the Governor of the British colony of New South Wales. However, by 
the 1830s controls had been largely lifted and seven papers had been established in the colony. As settlement spread to inland areas, the printing presses followed. In the 1890s it was observed that it was not unusual for towns of around 10,000 inhabitants to have four newspapers. Since the 1920s the trend has been toward a reduction in the number of titles and a concentration of ownership. In 1923 there were 26 dailies in Australia's six capital cities with 21 independent owners. By 1950 this had fallen to 15 dailies with ten owners. In 2014 Melbourne and Sydney have two daily newspapers, while all other capitals have one $(\rightarrow$ Concentration in Media Systems). The Australian newspaper industry is one of the most highly concentrated in the world. Rupert Murdoch's $\rightarrow$ News Corporation accounts for 70 percent of the total circulation of major papers in Australia. The other major players are John Fairfax Limited, with 21 percent of the circulation, and WA Newspapers, with 9 percent. The Internet has spawned a deep structural adjustment process in the industry. With print editions facing rapidly reduced circulations and advertising revenues, newspaper groups have focused on building up digital formats. While digital subscriptions are growing, advertising revenue is anticipated to continue shrinking in the period 2014-17.

There is a dual system of radio and television broadcasting with two state-owned networks operating side by side with government-licensed commercial operators. Regular radio broadcasting began in 1923. In 1932 twelve existing radio stations were nationalized and formed the basis of the Australian Broadcasting Commission (ABC), modeled on the $\rightarrow \mathrm{BBC}$. The $\mathrm{ABC}$ now operates four national radio networks. A second publicly funded network, the Special Broadcasting Service (SBS), was established in 1978 and currently broadcasts in 68 languages to all major centers in Australia ( $\rightarrow$ Public Broadcasting Systems; Television Broadcasting, Regulation of). In 2010 there were about 270 commercial radio stations and 350 community radio licenses ( $\rightarrow$ Community Media). Regular commercial and public service television broadcasting began in 1956. There is a strong tradition of public service television through the ABC and SBS. As well as its general programming, the latter operates a National Indigenous Television channel $(\rightarrow$ Ethnic Journalism; Ethnic Media and their Influence).

Commercial radio and television broadcasters are regulated by a licensing system administered by the Australian Communications and Media Authority (ACMA). The principle that has underpinned television regulation has been that, as spectrum allocation involves leasing a scarce and powerful resource to private interests, it is appropriate to attach conditions to licenses which reflect the public interest. These conditions cover programming (e.g., requirements for Australian content) and codes of practice. Australia's commercial free-to-air television system is dominated by three networks, Channels Seven, Nine, and Ten. Subscription television was introduced in 1995, utilizing both cable and satellite delivery systems ( $\rightarrow$ Cable Television; Satellite Television). The most powerful player in the Australian subscription television landscape is Foxtel, which had about 2.5 million subscribers in 2013 .

The first decade of the twenty-first century saw major changes to the structure and regulation of the Australian media arising from the switch from analog to digital broadcasting, and the increasing number of available media distribution platforms, especially the Internet. The government is furthering growth in the digital economy through its rollout of a new national broadband network at a cost of over $\$ \mathrm{~A} 40$ billion.

\section{See also: BBC CABLE TELEVISION \\ COMMUNICATION AND LAW COMMUNITY MEDIA CONCENTRATION IN MEDIA SYSTEMS ETHNIC JOURNALISM $>$ ETHNIC MEDIA AND THEIR INFLUENCE $>$ FREEDOM OF COMMUNICATION FREEDOM OF THE PRESS, CONCEPT OF NEWS CORPORATION PUBLIC BROADCASTING SYSTEMS D RADIO: SOCIAL HISTORY SATELLITE TELEVISION \\ TELEVISION BROADCASTING, REGULATION OF TELEVISION: SOCIAL HISTORY}

\section{REFERENCES AND SUGGESTED READINGS}

Commonwealth of Australia (Australian Communication and Media Authority) (2013). Communications report 2012-13. At www.acma.gov.au/commsreport, accessed July 15, 2014.

Griffen-Foley, B. (2010). Radio. In S. Cunningham \& G. Turner (eds.), The media and communication in Australia, 3rd edn. Sydney: Allen and Unwin, 113-131.

Tiffen, R. (2010). The press. In S. Cunningham \& G. Turner (eds.), The media and communication in Australia, 3rd edn. Sydney: Allen and Unwin, 81-95. 